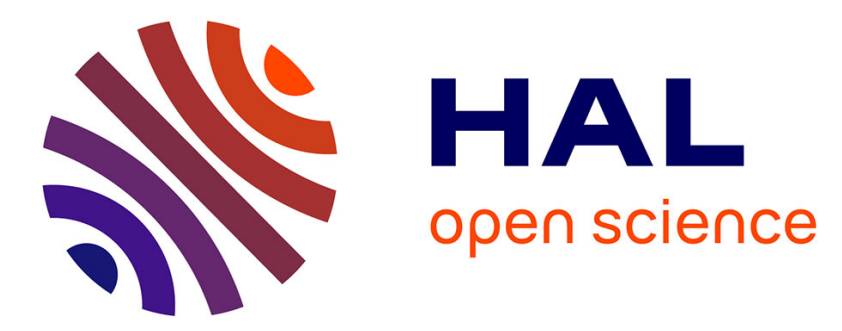

\title{
Sunglint correction of the Multi-Spectral Instrument (MSI)-SENTINEL-2 imagery over inland and sea waters from SWIR bands
}

\author{
Tristan Harmel, Malik Chami, Thierry Tormos, Nathalie Reynaud, \\ Pierre-Alain Danis
}

\section{To cite this version:}

Tristan Harmel, Malik Chami, Thierry Tormos, Nathalie Reynaud, Pierre-Alain Danis. Sunglint correction of the Multi-Spectral Instrument (MSI)-SENTINEL-2 imagery over inland and sea waters from SWIR bands. Remote Sensing of Environment, 2018, 204, pp.308-321. 10.1016/j.rse.2017.10.022 . insu-01628728

\section{HAL Id: insu-01628728 \\ https://hal-insu.archives-ouvertes.fr/insu-01628728}

Submitted on 5 Jan 2018

HAL is a multi-disciplinary open access archive for the deposit and dissemination of scientific research documents, whether they are published or not. The documents may come from teaching and research institutions in France or abroad, or from public or private research centers.
L'archive ouverte pluridisciplinaire HAL, est destinée au dépôt et à la diffusion de documents scientifiques de niveau recherche, publiés ou non, émanant des établissements d'enseignement et de recherche français ou étrangers, des laboratoires publics ou privés. 


\title{
Sunglint correction of the Multi-Spectral Instrument (MSI)-SENTINEL-2 imagery over inland and sea waters from SWIR bands
}

\author{
Tristan Harmel $^{\mathrm{a}, \mathrm{b}, *}$, Malik Chami ${ }^{\mathrm{c}, \mathrm{d}}$, Thierry Tormos ${ }^{\mathrm{e}}$, Nathalie Reynaud ${ }^{\mathrm{b}}$, Pierre-Alain Danis ${ }^{\mathrm{e}}$ \\ a Sorbonne Universités, UPMC Univ Paris 06, INSU-CNRS, Laboratoire d'Océanographie de Villefranche, 181 Chemin du Lazaret, 06230 Villefranche sur Mer, France \\ b Irstea, UR RECOVER, Pôle AFB-Irstea Hydroécologie des Plans d'eau, 3275 route Cézanne, F-13182 Aix-en-Provence, France \\ ' Sorbonne Universités, UPMC Univ Paris 06, INSU-CNRS, Laboratoire Atmosphères Milieux Observations Spatiales (LATMOS), 4 place Jussieu, 75252 Paris Cédex 5 , \\ France \\ d Institut Universitaire de France, 1, rue Descartes, 75231 Paris Cedex 05, France \\ e Agence Française pour la Biodiversité, Pôle AFB-Irstea Hydroécologie des Plans d'eau, UR RECOVER, 3275 route Cézanne, F-13182 Aix-en-Provence, France
}

\begin{abstract}
A B S T R A C T
Remote sensing of inland and sea waters depends on the quality of the retrieval of the water-leaving radiance from the top-of-atmosphere measurements. The water-leaving radiance can be difficult to observe due to the reflection of direct sunlight on the air-water interface (sunglint) in the direction of the satellite field of view. The viewing geometry of Sentinel-2 satellite (European Space Agency) makes it vulnerable to sunglint contamination. In this paper, an original method is proposed to correct Sentinel-2-like imagery for sunglint contamination. The sunglint contribution is first estimated from the shortwave-infrared (SWIR) part of the spectrum and then extrapolated toward the near-infrared and visible bands. The spectral variation of the sunglint signal is thus revisited for a wide spectral range (from 350 to $2500 \mathrm{~nm}$ ). The bidirectional reflectance distribution function related to the sunglint is shown to vary by $>28 \%$ from the SWIR to the blue bands of Sentinel-2. The application of the proposed algorithm on actual Sentinel-2 data demonstrates that sunglint patterns are satisfactorily removed over the entire images whatever the altitude of the observed target. Comparison with in situ data of water-leaving radiances (AERONET-OC) showed that our proposed algorithm significantly improves the correlation between satellite and in situ data by $55 \%$ (i.e., from $R^{2}=0.56$ to $R^{2}=0.87$ ). In addition, the discrepancies between satellite and in situ measurements are reduced by $60 \%$. It is also shown that the aerosol data provided by the Copernicus Atmosphere Monitoring Service (CAMS) can be safely used within the proposed algorithm to correct the Sentinel-2-like satellite data for both sunglint and atmospheric radiances. Improvements of the proposed method potentially rely on simultaneous retrievals of the aerosol optical properties. The proposed method is applicable to any satellite sensor which is able to measure in SWIR spectral bands over aquatic environments.
\end{abstract}

\section{Introduction}

Prior to reaching the satellite sensor, the sunlight undergoes numerous optical interactions within the atmosphere and aquatic systems (ocean, inland waters). For example, sunlight can be scattered or absorbed by gases and aerosols in the atmosphere, by water molecules, dissolved and particulate matter in the water column. In addition, sunlight is subjected to the reflection onto the water surface (the socalled "sunglint" phenomenon). The water-leaving radiance contributes no $>15 \%$ to the total radiance at the top of the atmosphere in the visible spectrum and much less when sunglint is present in the direction of the satellite viewing geometry.
Since the late 1970's, an international effort has been conducted to initiate, sharpen and reinforce passive remote sensing techniques in the visible and the near-infrared part of the spectrum for monitoring the global ocean. The first "ocean color" mission, the Coastal Zone Color Scanner (CZCS, 1978-1986), successfully demonstrated the feasibility of deriving pigment from space despite its poor spectral resolution (only spectral bands in the visible) (Gordon et al., 1983). Thanks to the experience acquired through the CZCS lifetime, a second generation of satellite missions was launched from the late 1990's with improved radiometric capabilities (e.g., SeaWiFS, MODIS, GLI, MERIS, VIIRS, OLCI) which all operate with a kilometer-scale spatial resolution. Thus, atmospheric correction algorithms were especially developed for the

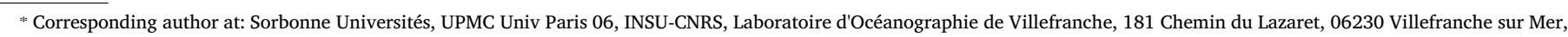
France.

E-mail address: harmel@obs-vlfr.fr (T. Harmel). 
characteristics of those kilometer-scale pixels to retrieve the waterleaving radiance by exploiting the atmospheric radiance measured in the near-infrared (NIR) or the shortwave-infrared (SWIR) bands where the water-leaving signal is negligible (Gordon, 1997; Wang and Shi, 2007).

Recently, two similar multispectral radiometers were launched: the Operational Land Image (OLI) onboard the Landsat-8 satellite (Roy et al., 2014) in February 2013 (National Aeronautics and Space Administration, NASA), and the Multi-Spectral Instrument (MSI) onboard the twin satellites Sentinel-2A and B (Drusch et al., 2012) in June 2015 and March 2017 (European Space Agency, ESA), respectively. Both instruments have much finer spatial resolutions, ranging from 10 to $60 \mathrm{~m}$, than that of the previous "ocean color" satellite missions (typically by a factor 10 to 100). Such a high spatial resolution is of great interest for understanding and monitoring the inland and coastal aquatic systems from passive remote sensing at local, regional and global scales (Schaeffer et al., 2013; Palmer et al., 2015). However, since the modeling of the top-of-atmosphere radiation remains a challenging task for decameter-scale pixels in comparison to kilometer-scale pixels, a special attention should be paid to the performance of inverse algorithms, especially for the atmospheric correction step. In particular, the sunglint phenomenon leads to a strong radiation that often masks the radiation exiting the water column. In addition, Sentinel-2 platform operates at near-nadir viewing angles where sunglint is likely to contribute to the signal received at the satellite level (Harmel and Chami, 2013).

The estimation of the sunglint contribution existing on ocean color data acquired at $1 \mathrm{~km}$ spatial resolution typically relies on the Cox and Munk (CM) model (Cox and Munk, 1954a, 1954b). Such a model is used to determine the sunglint radiance component based on ancillary data of wind speed and wind direction (Wang and Bailey, 2001; Zhang and Wang, 2010). Note that the uncertainty in the surface wind speed is the major source of error relatively to the uncertainty in the modeling of the sea surface (Breon and Henriot, 2006; Fukushima et al., 2009). Conversely, the wave slope statistics as parameterized by the CM model are questionable when dealing with high resolution images (i.e., pixel edge $<100 \mathrm{~m}$ ) (Kay et al., 2009). Therefore, most of the "deglinting" methods developed for high spatial resolution imagery are based on the estimation of the sunglint signal without any a priori assumption on the actual sea state (Kay et al., 2009).

The first algorithms developed to correct for sunglint were designed to exploit the signal measured in the NIR where the contribution of the water-leaving radiance is assumed as virtually negligible (Hochberg et al., 2003; Philpot, 2007). Refinements of those methods, which were mainly developed for hyperspectral imagery, permitted to account for non-negligible water-leaving radiance in NIR by (i) the exploitation of the characteristics of the oxygen absorption peak around $760 \mathrm{~nm}$ (Kutser et al., 2009); (ii) the water-leaving spectral characteristics in NIR on a pixel-wise approach (Goodman et al., 2008); or (iii) statistics over a set of bright and dark pixels within the image (Hedley et al., 2005; Lyzenga et al., 2006; Martin et al., 2016). Another study proposed a scheme to perform sunglint correction along with the atmospheric correction based on one band in the shortwave-infrared (SWIR) (Heege and Fischer, 2000). These methods are based on regression analyses of the radiances in the visible with those measured in the NIR. The regressions are performed for a given region of interest (ROI) of the image. It is assumed that within the ROI: (i) glinted and glint-free pixels are present and (ii) the water signal is spatially homogeneous. The first condition may be difficult to fulfill when the image contains an almost constant level of glint in every pixel, which can occur when there are only small waves smaller than the pixels. The selection of ROI is therefore a critical step of those methods. Nevertheless, it has to be done manually through a visual inspection thereby restricting any operational use of those methods. On the other hand, the selection of nonglinted area might be questionable when the full image is impacted by sunglint. To overcome this limitation, a pixel-based approach is developed here based on an explicit formulation of the sunglint signal with a special attention paid to the sunglint spectral behavior from the SWIR to the visible wavelengths.

The MSI/Sentinel-2 sensor provides measurements in the SWIR part of the spectrum which could alleviate some previous assumptions made for the NIR part of the spectrum. First, absorption of water molecules is more pronounced in the SWIR than in the NIR wavelength range by more than one order of magnitude thereby reinforcing the assumption of "black water" in the SWIR. Second, the atmosphere is more transparent with a weak amount of diffuse light (i.e., lower contribution of aerosols and air molecules) making measurements more sensitive to the sunglint contribution at such wavelengths. As a result, "deglinting" methods could be potentially improved based on the exploitation of the SWIR data.

In this paper, a methodology is proposed to estimate the sunglint radiation over the entire visible/NIR spectrum from the analysis of the signal measured at SWIR wavelengths. Then, the sunglint contribution is removed from the top-of-atmosphere radiation for the Sentinel-2 satellite data acquired over coastal and inland waters. The paper is organized as follows. First, the theoretical formulation of the sunglint radiation over the visible-SWIR spectral range is described; a particular attention is paid to the water surface reflectivity spectral shape (Section 2 ). Then, the algorithm that is proposed for sunglint correction is outlined (Section 3). The validation and performances of the algorithm are analyzed using Sentinel-2 data over coastal and lake regions and in situ measurements (Section 4). Comparisons with other methods taken from the literature and the potential for making the proposed algorithm operational are discussed in Section 5.

\section{Theoretical background}

\subsection{Top-of-atmosphere signal and water-leaving radiance}

At the top-of-atmosphere (TOA) level, the measured radiance can be expressed as follows:

$L_{t}^{\mathrm{TOA}}\left(\theta_{s}, \theta_{v}, \Delta \varphi\right)=L_{\text {diff }}^{\mathrm{TOA}}\left(\theta_{s}, \theta_{v}, \Delta \varphi\right)+L_{g}^{\mathrm{TOA}}\left(\theta_{s}, \theta_{v}, \Delta \varphi\right)$,

where $\theta_{s}$ and $\theta_{v}$ are the solar and viewing zenith angles, respectively, and $\Delta \varphi$ is the relative azimuth between the sun and the sensor (Fig. 1). $L_{\text {diff }}^{\text {TOA }}$ is the diffuse component of the light reaching the satellite sensor. The diffuse radiance is defined as the sunlight radiation which has been scattered at least once within the atmosphere and/or the water column before reaching the sensor. $L_{g}{ }^{\mathrm{TOA}}$ is the direct radiance corresponding to the sunglint component which arises from single or multiple reflections of the direct downward sun radiation on the air/water interface without undergoing any atmospheric or water column

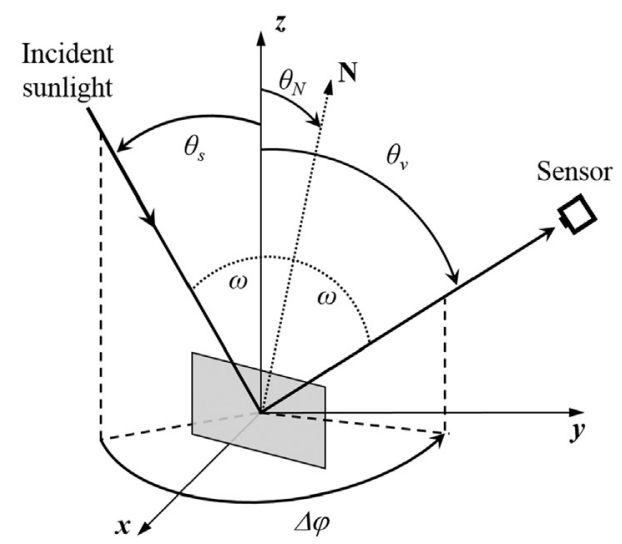

Fig. 1. Coordinate system and definition of the relevant geometry parameters: $\theta_{s}$ and $\theta_{v}$ are the solar and the viewing zenith angles, respectively, $\Delta \varphi$ is the relative azimuth. The vector $\mathrm{N}$ is the normal to the wave facet (gray area), $\theta_{N}$ is the angle of $\mathrm{N}$ with the vertical and $\omega$ is the specular reflection angle. 
scattering events.

As mentioned in Section 1, the water-leaving radiance is the radiometric quantity of interest to monitor ocean or inland waters content in particulate or dissolved matter. If the sunglint is ignored, the measured radiance corresponds to the diffuse TOA radiance which can be decomposed as follows:

$L_{\text {diff }}^{\mathrm{TOA}}\left(\theta_{s}, \theta_{v}, \Delta \varphi\right)=L_{\text {atm }}^{\mathrm{TOA}}\left(\theta_{s}, \theta_{v}, \Delta \varphi\right)+t_{u}\left(\theta_{s}, \theta_{v}, \Delta \varphi\right) L_{w}^{\mathrm{BOA}}\left(\theta_{s}, \theta_{v}, \Delta \varphi\right)$.

Here, $L_{a t m}{ }^{\text {TOA }}$ is the intrinsic atmospheric radiance accounting for the reflection of skylight on the water surface. $L_{w}{ }^{{ }^{B O A}}$ is the water-leaving radiance at the bottom of atmosphere and $t_{u}$ is the upward radiance transmittance which accounts for the light propagation through the atmosphere from the bottom to the top (Yang and Gordon, 1997).

\subsection{Sunglint radiance}

The sunglint component of the measured radiance, $L_{g}{ }^{T O A}$, can be straightforwardly formulated as follows:

$L_{g}^{\mathrm{TOA}}\left(\theta_{s}, \theta_{v}, \Delta \varphi\right)=T_{u}\left(\theta_{v}\right) B R D F_{\text {surf }}\left(\theta_{s}, \theta_{v}, \Delta \varphi\right) T_{d}\left(\theta_{s}\right) L_{\text {sun }}^{\downarrow}\left(\theta_{s}\right)$,

where $L_{\text {sun }} \downarrow$ is the extraterrestrial sun radiance reaching the atmosphere, $T_{d}$ and $T_{u}$ are the downward and upward direct transmittance, respectively, and $\mathrm{BRDF}_{\text {surf }}$ is the bidirectional reflectance distribution function of the rough water surface.

If the ocean surface is roughened by the wind, a myriad of reflected images of the sun will reach the satellite sensor due to specular reflection from various waves and wavelets of the sea surface. Following Cox and Munk (Cox and Munk, 1954b, 1956), the ocean surface can be modeled based on a distribution of small facets. The orientation of the facets can be fully described by their slopes $\zeta_{x}$ and $\zeta_{y}$ along the $x$ and $y$ axis of Fig. 1. The slopes $\zeta_{x}$ and $\zeta_{y}$ of facets contributing to sun light reflection toward the satellite sensor (sunglint signal) can be expressed based on the viewing configuration as follows:

$\zeta_{x}=\frac{\partial z}{\partial x}=-\left(\sin \theta_{s}+\sin \theta_{v} \cos \Delta \varphi\right) /\left(\cos \theta_{s}+\cos \theta_{v}\right)$,

$\zeta_{y}=\frac{\partial z}{\partial y}=-\left(\sin \theta_{v} \cos \Delta \varphi\right) /\left(\cos \theta_{s}+\cos \theta_{v}\right)$.

The proportion of such facets can be related to the wave slopes distribution. In addition, an accurate parameterization of the sunglint requires the consideration of the multiple reflections on the wave facets (Ottaviani et al., 2008; Li et al., 2013) and of wave shadowing effects (Ross et al., 2005), which depend on the wave height $h$. Several studies introduced different formulations of a function $q$ which merges the wave slope distribution with observable effects of multiple reflections and shadowing (Plass et al., 1975; Ross et al., 2005). Whatever the parameterization of $q$, the BRDF of the air/water interface can be formulated as follows:

$\mathrm{BRDF}_{\text {surf }}=\frac{\pi R_{f}(\omega)}{4 \cos \theta_{\nu} \cos ^{4} \theta_{N}} q\left(\zeta_{x}, \zeta_{y}, h\right)$,

where $R_{f}$ is the Fresnel reflection coefficient. Although Eq. (5) is applicable to a point source, it has been shown that the use of the Sun's irradiance produces an error smaller than $1 \%$ on the resulting observed reflected radiance for any slope variance as long as the Sun is $>10^{\circ}$ above the horizon (Ross et al., 2005).

\subsection{Spectral variation of the sunglint signal from $350 \mathrm{~nm}$ to $2500 \mathrm{~nm}$}

In this section, the spectral properties of the sunglint radiance are investigated over the spectral range operated by Sentinel-2-like satellites, namely, from the UV-visible $(350 \mathrm{~nm})$ to the SWIR $(2500 \mathrm{~nm})$ bands. The spectral variations of the sunglint radiance originate from that of (i) the extraterrestrial solar irradiance spectrum, (ii) the direct transmittance of the atmosphere, and (iii) the BRDF (Eq. (5)). The extraterrestrial solar irradiance is known from tabulated data (Thuillier et al., 2003). The atmospheric transmission depends on the optical depth of the different atmospheric constituents such as gases and aerosols. A particular attention has been paid to the direct transmittances calculation in the proposed algorithm according to the scattering and absorption properties of the gases and aerosols in presence (see Section 3). The last source of spectral variability of the sunglint comes from the BRDF of the air-water interface through the $R_{f}$ coefficient. A specific sensitivity analysis, which is detailed in Appendix, has been conducted to characterize the spectral variation of the BRDF. We report hereafter the main results of the sensitivity analysis.

Simulations based on different datasets or parameterizations of the refractive index of liquid water $n$ showed that the spectral variation of $n$ is about $4 \%$ from visible to SWIR wavelengths (see Fig. A.1 in Appendix). Such a variation induces a strong spectral dependence of the $R_{f}$ over the spectrum 350 to $2500 \mathrm{~nm}$, due to the non-linear relationship between $n$ and $R_{f}$. This dependence is increased for smaller incident angles $\omega$; typically by $>30 \%$ when the incident light is nearly perpendicular to the wave facet (see Fig. A.2a in Appendix). However, it is observed that the sunglint spectral variation is not significantly impacted by changes in salinity or temperature of water for the viewing geometry of observation of the Sentinel-2 platform (i.e., near-nadir viewing angles), (see Fig. A.2b). Note that the spectral ratio $\varepsilon=\mathrm{BRDF}_{\text {surf }}(\lambda) / \mathrm{BRDF}_{\text {surf }}\left(\lambda_{\text {ref }}=2190 \mathrm{~nm}\right)$ is slightly dependent on the viewing zenith and azimuth angles as well as the solar angle in comparison to the variation of $R_{f}$ with the incident angle $\omega$. Therefore, the sunglint signal can be handled from visible to SWIR measurements independently of water temperature and salinity in the case of MSI/ Sentinel-2 (or Landsat) configuration.

\subsection{Brief summary of the existing methods for sunglint removal}

Several deglinting techniques were developed based on regression analyses over the image (see (Kay et al., 2009) for a comprehensive review of those techniques). Such type of methods makes use of an implicit formulation of the spectral dependency of the sunglint signal expressed in reflectance (Hochberg et al., 2003; Hedley et al., 2005; Hu, 2011) such as:

$R_{\text {corr }}(\lambda)=R_{t}(\lambda)-\alpha(\lambda)\left(R_{t}\left(\lambda_{\mathrm{NIR}}\right)-\beta\right)$,

where $R_{t}$ is the reflectance at the top-of-atmosphere level, $R_{\text {corr }}$ is the top-of-atmosphere reflectance that is corrected for the sunglint contribution, $\alpha$ and $\beta$ are two parameters that are determined during the correction procedure.

In (Hochberg et al., 2003; Hedley et al., 2005), the parameter $\beta$ is taken as the minimum value of $R_{t}\left(\lambda_{\mathrm{NIR}}\right)$ within a given region of the image assuming that some of the observed pixels are virtually not contaminated by the sunglint radiance. The coefficient $\alpha$ is retrieved based on linear regressions between the reflectances measured in the NIR and the reflectances measured in the visible band. The reflectance values of the two spectral bands are fitted with the following equation:

$R_{t}^{\mathrm{TOA}}(\lambda)=\alpha(\lambda) R_{t}^{\mathrm{TOA}}\left(\lambda_{\mathrm{NIR}}\right)+$ offset

Those regressions are obtained for a part of the image where glinted and glint-free pixels should be present and where the water signal might be assumed as spatially homogeneous. Practically, such a region has to be selected "manually" by the user through a visual inspection of the entire image. Once $\alpha$ and $\beta$ are retrieved, Eq. (6) is used to obtain the sunglint-corrected reflectance $R_{\text {corr }}$. It is worth noting that $R_{\text {corr }}$ is not corrected for the atmosphere contribution. In order to retrieve the water-leaving signal, a proper atmospheric correction needs to be applied in addition to this type of deglinting methods. 
Table 1

Characteristics of the Sentinel-2/MSI spectral bands.

\begin{tabular}{|c|c|c|c|c|c|c|c|c|c|c|c|c|c|}
\hline Central wavelength (nm) & 443 & 490 & 560 & 665 & 705 & 740 & 783 & 842 & 865 & 945 & 1375 & 1610 & 2190 \\
\hline Band width (nm) & 20 & 65 & 35 & 30 & 15 & 15 & 20 & 115 & 20 & 20 & 30 & 90 & 180 \\
\hline Spatial resolution (m) & 60 & 10 & 10 & 10 & 20 & 20 & 20 & 10 & 20 & 60 & 60 & 20 & 20 \\
\hline
\end{tabular}

Table 2

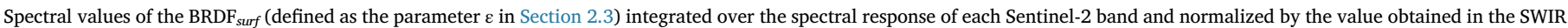
band at $2190 \mathrm{~nm}$.

\begin{tabular}{|c|c|c|c|c|c|c|c|c|c|c|c|}
\hline Band (nm) & 443 & 490 & 560 & 665 & 705 & 740 & 783 & 842 & 865 & 945 & 1610 \\
\hline Spectral ratio $\varepsilon$ & 1.2862 & 1.2668 & 1.2496 & 1.2304 & 1.2248 & 1.2203 & 1.2155 & 1.2099 & 1.2066 & 1.1985 & 1.1246 \\
\hline
\end{tabular}

\section{Algorithm for sun glint removal of Sentinel-2-like images (GRS)}

\subsection{Main characteristics of the MSI/Sentinel-2 sensor}

The Sentinel-2 mission (ESA) has been designed to provide multispectral high spatial-resolution optical observations over global terrestrial surfaces, including the monitoring of vegetation, soil and inland/coastal waters (Drusch et al., 2012). Sentinel-2 carries the Multispectral Instrument (MSI) which is a wide-swath, high-resolution, multi-spectral imaging system. MSI operates at 13 spectral bands with different spatial resolutions ranging from $10 \mathrm{~m}$ to $60 \mathrm{~m}$ (Table 1). It is worth noting that the viewing and azimuth angles only slightly vary from one spectral band to another given a pixel; the viewing angles are smaller than $10^{\circ}$ over the acquired image. Table 2 provides the spectral ratio of $\mathrm{BRDF}_{\text {surf }}$ values (normalized to $\lambda_{\text {ref }}=2190 \mathrm{~nm}$ ) which were calculated following the methodology detailed in Appendix. Note that the true relative spectral response of the MSI/Sentinel-2 sensor was used for that purpose. The spectral dependence of the BRDF could reach about $28.6 \%$ between $443 \mathrm{~nm}$ and $2190 \mathrm{~nm}$ (Table 2).

\subsection{GRS algorithm}

Based on the spectral characteristics of the sunglint radiance that was observed in Section 2 (and Appendix), an algorithm, was developed to (i) estimate the sunglint radiation over the entire visible/NIR spectrum using the SWIR bands and (ii) to correct the MSI/Sentinel-2 data acquired over oceanic/inland waters for the sunglint component of the signal.

Fig. 2 provides the flowchart of the proposed GRS algorithm,. The main principle of the algorithm is to derive the BRDF values of the airwater interface in the SWIR bands for which the atmosphere is weakly impacted by scattering of air molecules and aerosols. SWIR bands are preferentially examined because the water-leaving radiance can be assumed null due to the high absorption of the oceanic radiation by the water molecules at these wavelengths (Hale and Querry, 1973). Note that a null water-leaving radiance at SWIR bands is generally true even for the most turbid waters (Shi and Wang, 2009). The algorithm requires as well a prior knowledge of the optical properties of the aerosols. In this paper, the aerosol properties are taken from in situ measurements collected by the AERONET network (Holben et al., 1998) or model-based data provided by the Copernicus Atmosphere Monitoring Service (CAMS) (Hollingsworth et al., 2008; Flemming et al., 2017). Once the BRDF value is retrieved in the SWIR, the sunglint radiance in the visible-NIR bands is calculated based on the BRDF spectral dependence that was characterized in Table 2 . Thus, the sunglint radiation can be further subtracted from the measured satellite radiances to get the normalized water-leaving radiances for all the Sentinel-2 bands.

Since the spectral bands of MSI have different spatial resolutions, the first step is to resample the different bands on a common grid. To make the SWIR information meaningful for the other bands, the

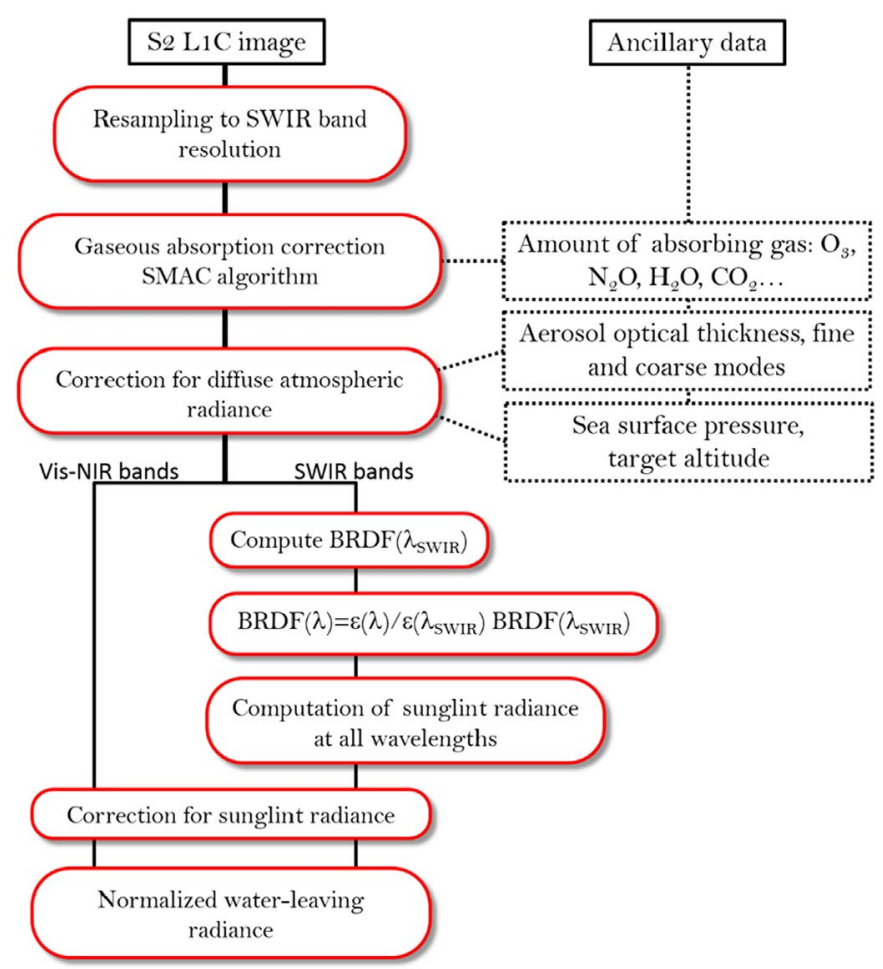

Fig. 2. Flowchart of the proposed GRS algorithm to remove the sunglint contribution from the MSI/Sentinel-2 images.

Sentinel-2 image is reprojected on the grid of the 2190-nm band for a spatial resolution of $20 \mathrm{~m}$. It is worth noting that the low signal-to-noise ratio (SNR) of the SWIR bands of Sentinel-2 is not a major issue for the sunglint removal. The SNR is typically low when no sunglint is present in the scene but, in this case, it is not necessary to perform any sunglint correction. Conversely, when pixels are contaminated by the presence of sunglint, the sunglint signal will enhance the SNR of the SWIR bands more rapidly than that of the visible bands due to the higher value of atmospheric transmission in the SWIR channels.

The radiance data as well as the viewing and azimuth angles of each band are reprojected using the Sentinel-2 toolbox that is publicly available (http://step.esa.int/main/toolboxes/sentinel-2-toolbox). Based on the viewing and solar angles, the spectral radiances are corrected for the gaseous absorption through the last version of the SMAC algorithm (Rahman and Dedieu, 1994). In SMAC algorithm, the transmittances for each absorbing gas are parameterized using an exponential relationship with the gas content and using the viewing geometry (sun and viewing angles). These parameterizations were generated using the 6S code (Kotchenova et al., 2006) for standard vertical profiles of the main absorbing gases $\left(\mathrm{CO}_{2}, \mathrm{H}_{2} \mathrm{O}, \mathrm{N}_{2} \mathrm{O}, \mathrm{O}_{3} \ldots\right)$ and 
by taking into account the spectral response of the Sentinel-2 bands. Here, the $\mathrm{H}_{2} \mathrm{O}$ and $\mathrm{O}_{3}$ content are taken from the European Centre for Medium-Range Weather Forecasts (ECMWF) global forecast dataset (Dee et al., 2011). The content of the other gases was considered constant over time.

After the correction of the radiances for the gaseous absorption, the radiance is corrected for the atmospheric diffuse radiance to get both the water-leaving and the sunglint components. Following the formulation of Eqs. (1) and (2), and dropping off the viewing geometry dependency for brevity, the correction of the total radiance for the atmospheric radiance is written as:

$L_{t}^{\mathrm{TOA}}(\lambda)-L_{a t m}^{\mathrm{TOA} *}(\lambda)=t_{u}(\lambda) L_{w}^{\mathrm{BOA}}(\lambda)+L_{g}^{\mathrm{TOA}}(\lambda)$,

where $L_{a t m}^{T O A *}$ is the simulated intrinsic atmospheric radiance including reflection of the sky light on the air-water interface. Within the algorithm, this term is calculated for the given viewing geometry based on radiative transfer simulations archived in look-up tables (LUT). Those LUTs were generated using the OSOAA code (Chami et al., 2015) which numerically solves the radiative transfer equation for the coupled system of atmosphere and water body with a rough air-water interface considering the linear polarization state of light. Extended computations were achieved for all the viewing geometry $\left(\theta_{s}, \theta_{v}, \Delta \varphi\right)$ with increments of $1.5^{\circ}$ for $\theta_{s}$ and $\theta_{v}$ and $5^{\circ}$ for $\Delta \varphi$ and for aerosol optical thicknesses ranging from 0.0001 to 1 at $550 \mathrm{~nm}$. The Rayleigh optical thicknesses is taken from tabulated values (Bodhaine et al., 1999) and integrated over the spectral response of each MSI band. In addition, the effect of atmospheric pressure is taken into account following (Wang, 2016). Note that the pressure at the target altitude, $h$ (in meter), is calculated from the pressure at the sea level, $P(0)$ in $\mathrm{hPa}$, assuming the international standard vertical profile of temperature:

$P(h)=P(0)\left[1-\frac{0.0065 h}{288.15}\right]^{5.255}$,

where $P(0)$ value is taken from the ECMWF dataset.

The aerosols are assumed to follow a bimodal size distribution following several studies which showed that a satisfactory simulation of aerosols can be obtained using a mixture of a fine mode with a coarse mode (e.g., Kaufman et al., 2001; Veselovskii et al., 2004). The optical properties of the fine and coarse aerosol modes considered in the LUT were computed from the models 4 and 7 of the MODIS aerosol collection 5 (Levy et al., 2009) corresponding to a mean radius of 0.1 and $0.8 \mu \mathrm{m}$ for the fine and coarse modes, respectively. The atmospheric radiance $L_{a t m}{ }^{T O A *}$ is computed within the algorithm based on a simple weighted sum of the fine and coarse modes contributions which was shown to be accurate for the viewing angles considered here (Wang and Gordon, 1994):

$L_{\text {atm }}^{\mathrm{TOA} *}(\lambda)=\gamma L_{\text {atm }}^{\mathrm{TOA} *}\left(\lambda, \tau_{a}\right.$, fine $)+(1-\gamma) L_{\text {atm }}^{\mathrm{TOA} *}\left(\lambda, \tau_{a}\right.$, coarse $)$,

where fine and coarse stand for the microphysical properties of the respective aerosol modes, $\tau_{a}$ is the total aerosol optical thickness at $550 \mathrm{~nm}$ corresponding to the sum of the fine and coarse optical thicknesses $\left(\tau_{a}=\tau_{a}^{f}+\tau_{a}^{c}\right)$. The term $\gamma$ is the mixing coefficient between the two aerosol modes which is defined as $\gamma=\tau_{a}^{f} / \tau_{a}$. In the proposed algorithm, the $\gamma$ coefficient is retrieved as follows. First, following (Eck et al., 1999), a second order polynomial is used to model the spectral variation of $\tau_{a}$ :

$\log \left(\tau_{a}(\lambda)\right)=a_{0}+a_{1} \log (\lambda)+a_{2} \log (\lambda)^{2}$.

Here, the parameters $\mathrm{a}_{0-2}$ are retrieved by fitting the function of Eq. (11) upon available exogenous data of the aerosol optical thickness spectral values. In the following, those aerosol data are taken from either the AERONET or CAMS datasets. Afterward, the mixing ratio of the fine and coarse modes is retrieved by fitting the $\tau_{\mathrm{a}}$ spectral values obtained from Eq. (11) with those of the bimodal aerosol model $\tau_{a_{s} s i m}$ : $\tau_{\text {asim }}(\lambda)=\gamma \tau_{a s i m}^{\text {fine }}(\lambda)+(1-\gamma) \tau_{a s i m}^{\text {coarse }}(\lambda)$

Assuming that the water-leaving radiance is null in the SWIR bands, one can combine Eqs. (3) and (8) to express the BRDF of the air-sea interface for a given pixel:

$\operatorname{BRDF}\left(\theta_{s}, \theta_{v}, \Delta \varphi, \lambda_{\text {SWIR }}\right)=\frac{L_{g}^{\mathrm{TOA}}\left(\theta_{s}, \theta_{v}, \Delta \varphi, \lambda_{\text {SWIR }}\right)}{T\left(\lambda_{\text {SWIR }}, \theta_{v}\right) T\left(\lambda_{\text {SWIR }}, \theta_{s}\right) L_{\text {Sun }}^{\downarrow}\left(\theta_{s}\right)}$,

where the geometrical dependencies are explicitly expressed to highlight that the sunglint signal is highly directional. $T$ is the direct transmittance, which is defined as:

$T\left(\lambda, \theta_{i}\right)=\exp \left(-\frac{\tau_{r}(\lambda, P)+\tau_{a}(\lambda)}{\cos \theta_{i}}\right)$

Note that the gaseous absorption does not appear in Eq. (14) since correction of gaseous absorption was already achieved in the previous steps of the algorithm. Note that the retrieved BRDF values can be used to mask the non-glinted pixels (BRDF $\sim 0$ ) or to contribute to define a threshold value to eliminate strongly contaminated pixels. Once the BRDF is retrieved for the different SWIR bands available by the satellite sensor (i.e., two SWIR bands for MSI/Sentinel-2), the sunglint radiance can be calculated for every band by taking into account the BRDF spectral variation (Fig. A.2b) through the computed $\varepsilon$ values:

$L_{g}^{\mathrm{TOA}}(\lambda)=T\left(\lambda, \theta_{v}\right) T\left(\lambda, \theta_{s}\right) \frac{\varepsilon(\lambda)}{\varepsilon\left(\lambda_{\mathrm{SWIR}}\right)} \operatorname{BRDF}\left(\theta_{s}, \theta_{v}, \Delta \varphi, \lambda_{\mathrm{SWIR}}\right) L_{\text {sun }}^{\downarrow}\left(\lambda, \theta_{s}\right)$.

The spectral sunglint radiance is finally subtracted from the righthand side of Eq. (8) and the normalized-water leaving is computed independently for each pixel of the image in the visible part of the spectrum.

\section{Applications to Sentinel-2 imagery}

The GRS algorithm is applied to the level 1 images (L1C) of the Sentinel-2/MSI archive for several locations around the world. Those locations were selected according to the availability of ground-based measurements of the water-leaving radiances so that the performance of the method could be evaluated. The first set of available groundbased data relies on the ocean color component of the NASA Aerosol Robotic Network (AERONET-OC). Such a network has been designed to support long-term satellite ocean color investigations through cross-site consistent and accurate above-water measurements collected by autonomous radiometer systems that are deployed on offshore fixed platforms (Zibordi et al., 2009). Sentinel-2 images of the areas surrounding the different AERONET-OC sites are thus processed and analyzed. In addition, the site of Naussac reservoir (France; 44.75 N, 3.80E; altitude: 940 m.a.s.l.) was also selected since it is one of the pilot sites of the TELQUEL/CNES project that is dedicated to develop specific biooptical algorithms for inland waters (Tormos et al., 2015). As mentioned in Fig. 2, the multispectral aerosol optical thickness is considered as an ancillary data for the GRS algorithm. Here, those data are taken from the ground-based measurements of the AERONET photometers corresponding to the level 1.5 of the Direct Sun Algorithm version 3 (https://aeronet.gsfc.nasa.gov/cgi-bin/type_piece_of_map_aod_v3).

\subsection{Qualitative analysis}

The performances of the GRS algorithm are first assessed qualitatively based on couples of red-green-blue composite (RGB) images before and after removing the sunglint contribution. The RGB images have been generated from the normalized water-leaving radiance obtained for the Sentinel-2 bands centered on 490, 560 and $665 \mathrm{~nm}$. Note that the images have been first corrected for the atmospheric radiance (Eq. (8)). Therefore, the observed differences between those images can 

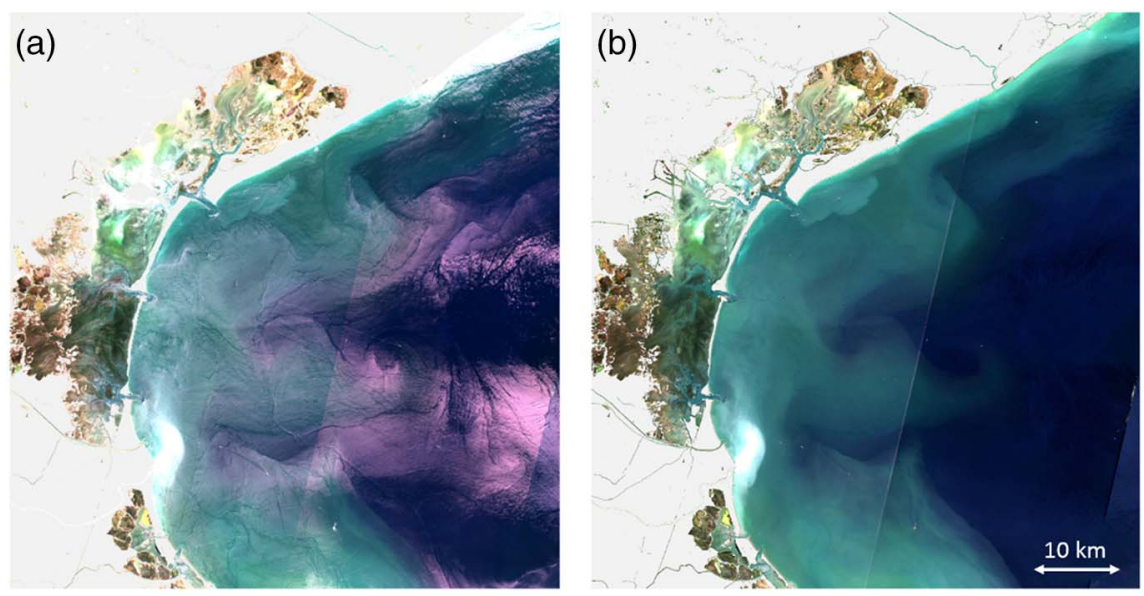

Fig. 3. RGB images obtained after subtraction of the atmospheric radiance from TOA signal but before (left column) and after (right column) removing the sunglint radiance. These images correspond to the areas surrounding the AERONET-OC sites of (a, b) Venice (July 18, 2016) and (c, d) WaveCIS (April 23,2016 ). Note that the same color scale was used to generate the RGB images before and after removing the sunglint radiance.

(c)

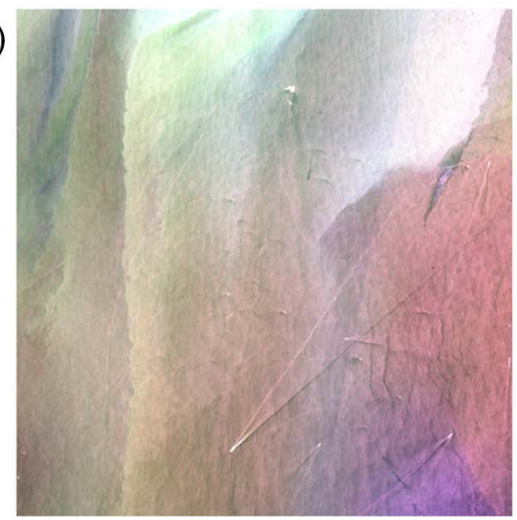

(d)

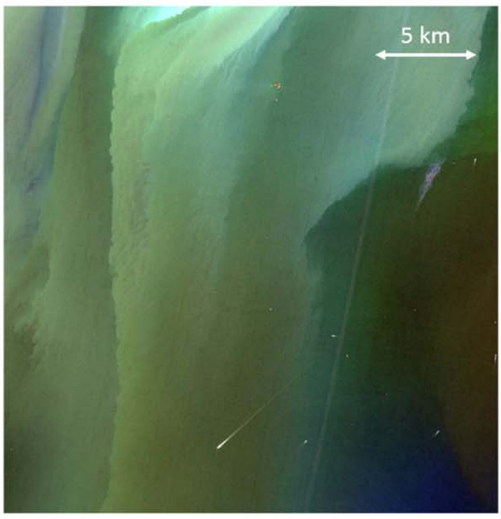

be attributed to the sunglint removal only.

Fig. 3 shows two couples of images acquired over two coastal sites: Venice site, located on the Adriatic Sea (Italy) (top row) and WaveCIS AERONET site, located at $120 \mathrm{~km}$ south of New Orleans (USA) in the Gulf of Mexico (bottom row). Before removing the sunglint radiance, the image of the Venice site exhibits, in addition to the water-leaving radiance patterns, conspicuous sunglint patterns recognizable by their violet hue on the RGB image. It can be readily observed that those patterns follow complex shapes with pronounced discontinuities over the entire image. As an example, this is particularly observed in the middle of the right-hand side of the image. After removing the sunglint radiance (Fig. 3b), all the noticeable discontinuities are removed. Instead of sunglint patterns, smooth variations of the radiance are observed which are consistent with the presence of more turbid waters in the vicinity of the coast.

The second couple of images of the WaveCIS site corresponds to a closer look within the Sentinel-2 scene. The presence of ships and their subsequent wakes are remarkable in the bottom-right corner of Fig. 3c. Indeed, it is well-known that a ship moving in deep water generates a Vshape wake, consisting of Kelvin waves, with a fixed half-angle of $19.5^{\circ}$ (e.g., Zilman and Miloh, 2001). On the other hand, ship wakes can significantly modulate the total reflected sunlight (Gatebe et al., 2011) thereby impacting sunglint pattern as observed from the satellite images. All the ship wake patterns are smoothed out after applying the GRS algorithm with the exception of thin white lines behind the ships which likely correspond to turbulence-induced bubbles in the subsurface waters.

Similarly to Fig. 3, Fig. 4 shows RGB images for an estuary area prior and after removing the sunglint radiance. The qualitative performances are evaluated over river and estuary waters in the vicinity of the Luncida AERONET site (East Australia; 146.39E, - 18.52 N) (Fig. $4 \mathrm{a}$ and $\mathrm{b}$ ). The left-hand side of the image corresponds to the main land with rivers ended to estuaries and the coastal zone. In the example of Fig. 4, the hue of the rivers is better distinguishable after removing the sunglint radiance. This is particularly true in the main estuary (middle of the image) where it can be readily observed that the water hue is restored in the end of the mouth and the plume after subtraction of the sunglint component.

The GRS algorithm is now tested for scenes corresponding to fresh waters that are located at an altitude much higher than the sea level. A Sentinel-2 image of the Naussac reservoir (France) that was acquired in July 7, 2016 is analyzed (Fig. 4c). Note that Naussac reservoir is located at an altitude of 940 m.a.s.l. As it can be observed in Fig. 4c, the image is highly contaminated by the sunglint. The sunglint contamination produces contrasted patterns over the entire lake area. After removing the sunglint radiance, the lake appears homogeneous throughout the RGB image of Fig. 4d. Therefore, the example of Fig. 4c and d illustrates the efficiency of the GRS method to correct for the sunglint radiance in the case of a high sunglint contamination including for areas that are located at a significant altitude.

Based on Figs. 3 and 4, the GRS algorithm performs well from a qualitative point of view to remove the spatial effects of the sunglint radiance. A similar conclusion was also obtained when dealing with many other images (not shown). It is worth reminding that the GRS algorithm relies on the processing of each pixel independently of the others (pixel-based approach). From this point of view, the elimination of the sharp and pronounced sunglint patterns is a first evidence demonstrating the effectiveness of the GRS algorithm for coastal and offshore waters as well as inland waters whatever the altitude of these inland targets.

\subsection{Quantitative validation}

The assessment of the GRS performances is quantitatively performed based on matchup comparison of the normalized water-leaving radiances $L_{W N}$ retrieved from the level 1 (L1C) Sentinel-2 data with the 

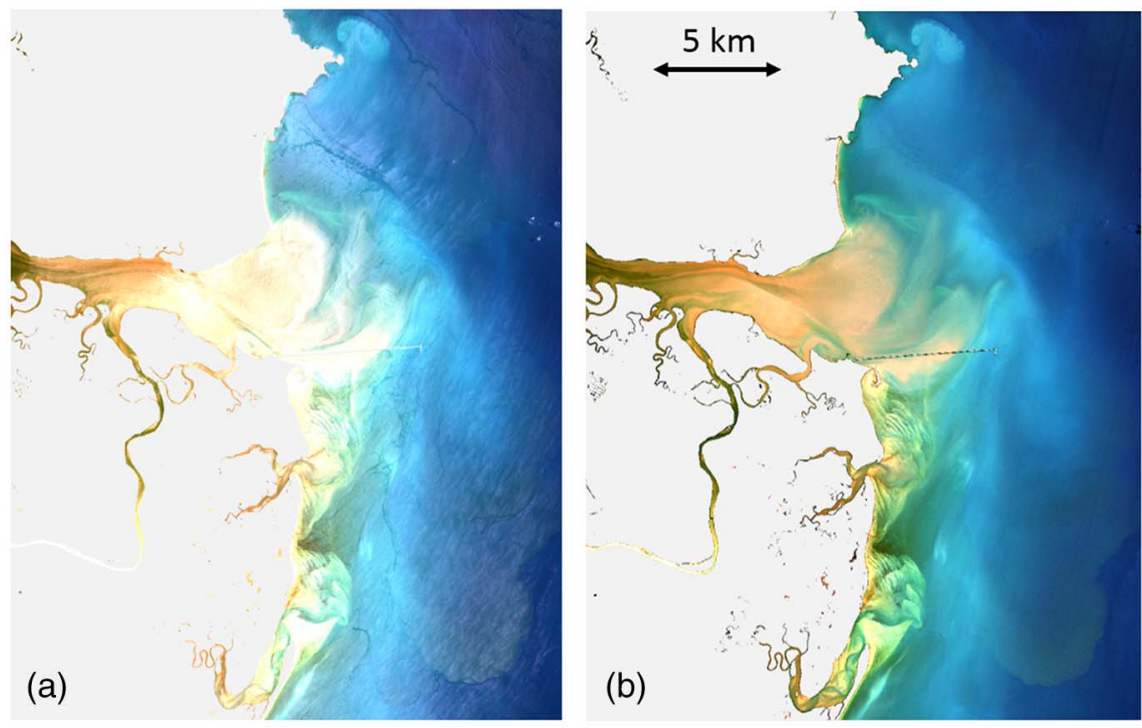

Fig. 4. Same as Fig. 3 but for estuary and lake areas: (a, b) Lucinda AERONET-OC site (estuary, Australia) (February 19, 2016) and (c, d) Naussac reservoir (France) (July 7, 2016).
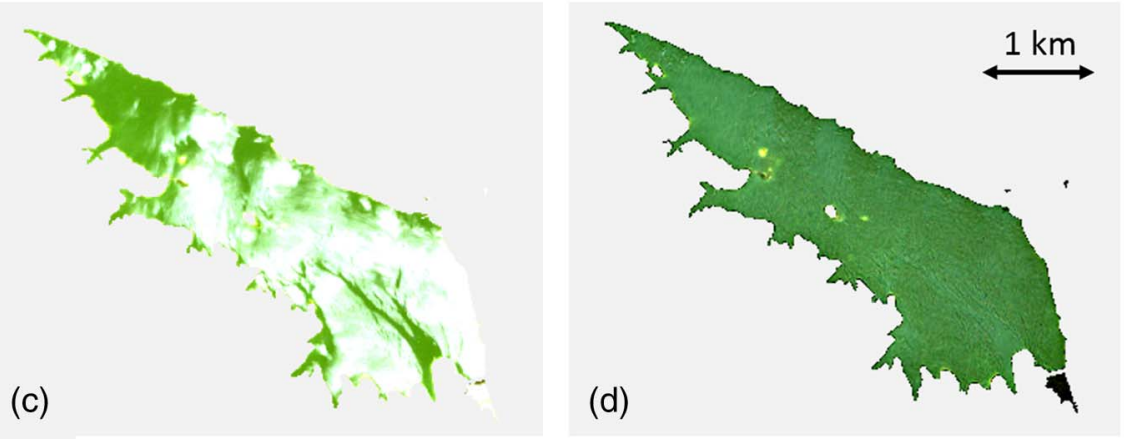

coincident data of the AERONET-OC sites. Such a comparison is carried out for the same spectral bands as AERONET-OC device, namely, 443, 490, 560, 665 and $865 \mathrm{~nm}$. The AERONET-OC data correspond to the level L1.5 quality controlled datasets. The mean, $25 \%$ and $75 \%$ quantiles are computed within a time window of plus or minus $3 \mathrm{~h}$ around the satellite overpass.

The Sentinel-2 data are taken from a $5 \times 5$ pixel box centered on the AERONET-OC site locations. A coarse cloud filtering is applied based on the Sentinel-2 L1C operational flag. The measured reflectance at $1375 \mathrm{~nm}$ (noted R1375) is used to filter out potential contamination by high clouds, i.e., pixels showing a value of R1375 $>310^{-3}$ are discarded. Finally, pixels showing at least three negative values in the visible bands are also excluded from the comparison since these pixels can be potentially impacted by cloud shadows. After such steps of filtering, boxes for which at least $50 \%$ of valid pixels remains are used for the comparison. For each spectral band, the median value is used to minimize potential impacts of the AERONET-OC platform which might be visible on a few pixels within the selected $5 \times 5$-pixel boxes.

The comparison between satellite and in situ data of water-leaving radiances is presented in Figs. 5 and 6 before and after removing the sunglint radiance, respectively. The statistics of the comparison are summarized for each spectral band within these figures. The statistical quantities that are further analyzed are as follows: equation of the linear regression line, coefficient of determination $R^{2}$, root-mean-square error RMSE and its normalized counterpart NRMSE (i.e., RMSE divided by the mean value of the in situ data) as well as the bias. The resulting comparison corresponds to a total number of 150 matchup points (i.e., 150 satellite images) for 16 AERONET-OC sites including 14 coastal sites (namely, COVE, Gageocho, Galata, Gloria, GOT, Gustav Dalen, Helsinki Lighthouse, LISCO, Lucinda, MVCO, Thornton C-power, USC, Venise, WaveCIS, Zeebrugge) and 2 lake sites (namely, Lake Erie, Pålgrunden).
Fig. 5 shows the results of the comparison between satellite and in situ data when the sunglint contribution is not removed yet. Despite the fact that the slope of the regression line is close to one (1.06), the satellite and ground-based data are poorly correlated $\left(R^{2}<0.56\right)$. The RMSE is significantly high $\left(0.78 \mathrm{~mW} \cdot \mathrm{cm}^{-2} \cdot \mathrm{sr}^{-1} \cdot \mu \mathrm{m}^{-1}\right)$ corresponding to a value of NRMSE of $138 \%$ with an important bias indicating an overestimation of $L_{W N}$ by $0.48 \mathrm{~mW} \cdot \mathrm{cm}^{-2} \cdot \mathrm{sr}^{-1} \cdot \mu \mathrm{m}^{-1}$ on average. When the sunglint component is removed from the image using the GRS algorithm (Fig. 6), the correlation between satellite and in situ data is significantly increased (i.e., value of $R^{2}$ of 0.87 ). Both the RMSE and the bias are reduced by $>60 \%$ (RMSE $=0.32 \mathrm{~mW} \cdot \mathrm{cm}^{-2} \cdot \mathrm{sr}^{-1} \cdot \mu \mathrm{m}^{-1}$, bias $=0.17 \mathrm{~mW} \cdot \mathrm{cm}^{-2} \cdot \mathrm{sr}^{-1} \cdot \mu \mathrm{m}^{-1}$ ) relatively to the case of Fig. 5 , thus demonstrating the effectiveness of the GRS algorithm. In addition, it is worth noting that the dispersion of the satellite data within the $5 \times 5$ pixel box (vertical bars in Figs. 5 and 6) is largely reduced after removing the sunglint signal. This can be explained by the fact that the sunglint component might be rapidly changing from one pixel to another (case of Fig. 5) while the spatial variation of actual water-leaving radiance is likely to be smoothed over a $5 \times 5$-pixel box (e.g., $100 \times 100 \mathrm{~m}^{2}$ ) (case of Fig. 6).

Fig. 6 shows that the improvements obtained after applying the GRS algorithm occur for each spectral band, especially for the band at $665 \mathrm{~nm}$ where $R^{2}$ is largely increased from 0.19 (Fig. 5) to 0.88 (Fig. 6). The RMSE value is significantly reduced as well by $75 \%$ after the sunglint correction. The best performances of GRS algorithm are observed for the bands at 490, 560 and $665 \mathrm{~nm}$ for which the spatial resolution is the highest $(10 \mathrm{~m})$. The lowest performances are observed for the band at $443 \mathrm{~nm}$ where $R^{2}$ is equal to 0.58 . This can be partly explained by the fact that the aerosol models used in GRS algorithm exhibit a weak absorption component (imaginary refractive index $n^{\prime}$ between 0.001 and 0.002) which may not be so realistic for some coastal areas where absorption by specific aerosols could be much more 

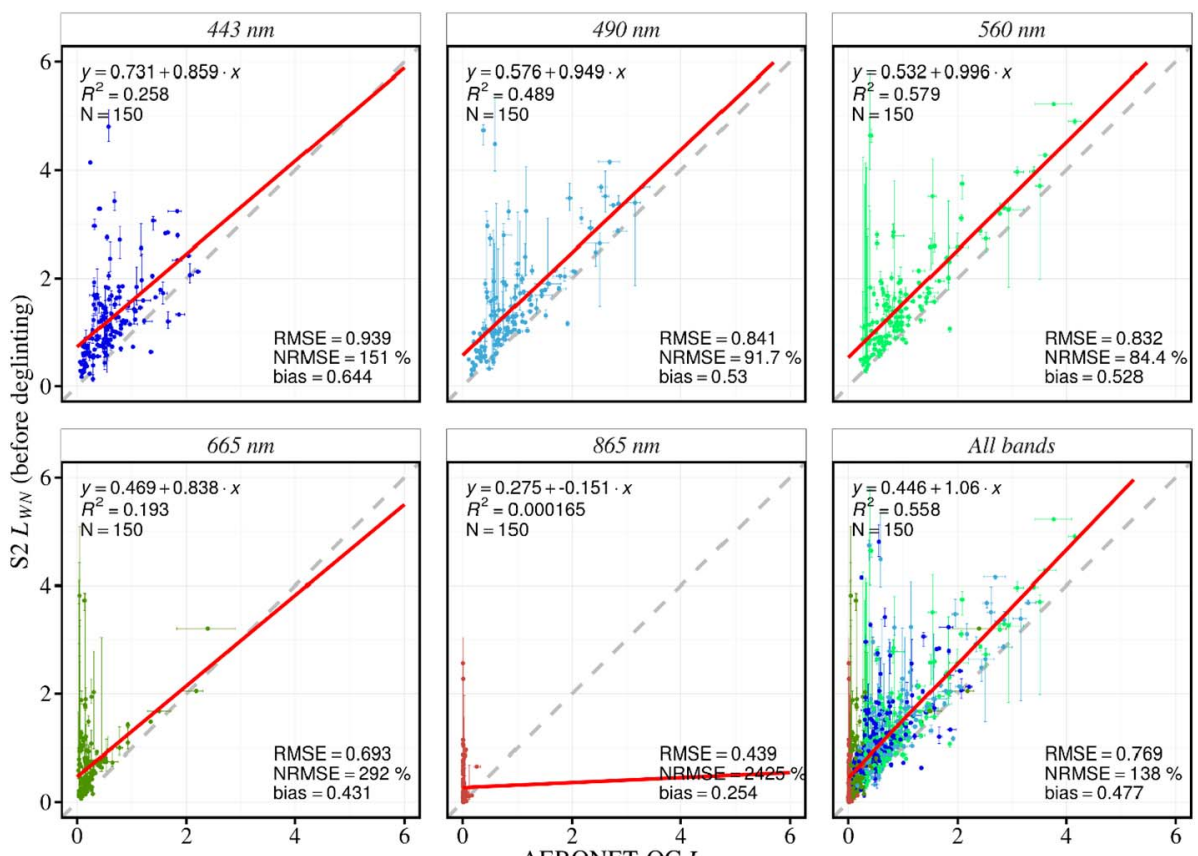

Fig. 5. Matchup comparison of the normalized waterleaving radiance $L_{W N}\left(\right.$ in $\mathrm{mW} \cdot \mathrm{cm}^{-2} \cdot \mathrm{sr}^{-1} \cdot \mu \mathrm{m}^{-1}$ ) between in situ AERONET-OC data and satellite Sentinel-2 data when the sunglint radiance has not been removed. Note that the atmospheric radiance (Eq. (8)) has been subtracted from the satellite data. Vertical and horizontal bars indicate the dispersion from the $25 \%$ to the $75 \%$ quantiles for satellite and AERONET-OC data, respectively.

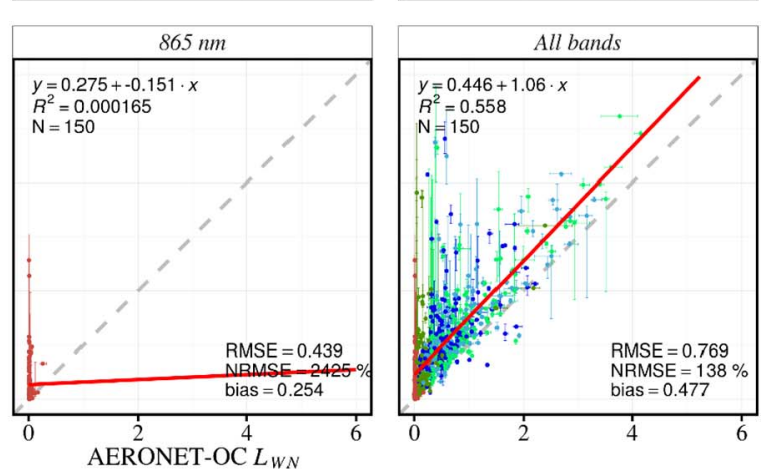

significant (by one order of magnitude) with values of $n^{\prime}$ that could be $>0.01$. Yet, the GRS method allows decreasing both RMSE and bias by a factor of two at $443 \mathrm{~nm}$. Note finally that the weak correlation that is observed at $865 \mathrm{~nm}\left(R^{2}=0.1\right)$ could likely be explained by the low values of $L_{W N}$ (almost black waters) at this wavelength which are corroborated by the weak bias $\left(0.07 \mathrm{~mW} \cdot \mathrm{cm}^{-2} \cdot \mathrm{sr}^{-1} \cdot \mu \mathrm{m}^{-1}\right)$.

The matchup comparison has been performed using a great number of Sentinel-2 images (150) and a large variety of water types from inland to sea waters, from oligotrophic to eutrophic conditions (Zibordi et al., 2009). The performances of the GRS method applied to Sentinel-2 data are similar to those obtained for the main ocean color satellite missions (MERIS, MODIS, SeaWiFS, VIIRS); which have been assessed using the same reference data provided by the AERONET-OC network (e.g., Mélin et al., 2007; Zibordi et al., 2009; Goyens et al., 2013; Hlaing et al., 2013). Therefore, the GRS method could be considered as a robust one from the point of view of the validation step. Our results clearly demonstrate the requirement of including the systematic correction of the sunglint contribution (in addition to the correction for the atmospheric radiance) in the MSI/Sentinel-2 data processing to correctly estimate the water-leaving radiance over contrasted waters at high spatial resolutions.

\section{Discussion}

\subsection{Comparison of GRS algorithm with other methods}

The proposed scheme for sunglint correction is based on a per-pixel approach and a full consideration of the physical basis underlying the
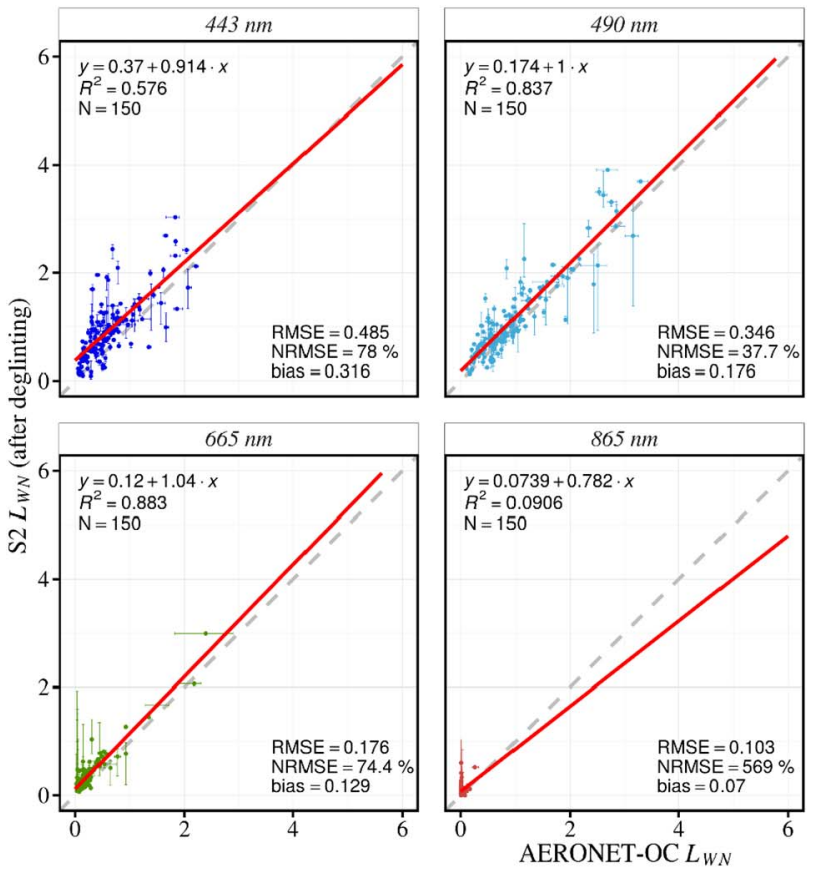

Fig. 6. Same as Fig. 5 but after removal of the sunglint radiance using the GRS algorithm. 
sunglint signal that reaches the satellite sensor. Several deglinting techniques were developed based on regression analyses over the image (see Section 2.4). In this section, we demonstrate that Eq. (6) used in the regression methods can be derived from the theoretical formalism used earlier in the paper. In addition, we discuss the performances of the current deglinting techniques (i.e., regression analyses as given by Eq. (6)) by comparison with the proposed GRS algorithm (i.e., physically-based method).

The main assumption that is made in the regression analyses techniques is that the sunglint reflectance $R_{g}$ can be retrieved in the NIR part of the spectrum as follows:

$R_{g}\left(\lambda_{\mathrm{NIR}}\right)=R_{t}\left(\lambda_{\mathrm{NIR}}\right)-R_{\text {atm }}\left(\lambda_{\mathrm{NIR}}\right)$.

Note that the water contribution is assumed negligible in Eq. (16). Thus, the parameter $\beta$ is simply the reflectance of the atmosphere (including sky reflection on the air-sea interface) $R_{a t m}$. In the proposed GRS method, the term $R_{a t m}$ is obtained pixel per pixel using exact radiative transfer calculations (through LUTs). Afterward, the sunglint signal needs to be calculated for each spectral band considering the spectral variation of the BRDF as previously explained in Section 3 (Fig. 2). Following the formalism of Eqs. (15) and (A6), and after converting the radiance into reflectance, the sunglint reflectance can be written:

$R_{g}(\lambda)=T\left(\lambda, \theta_{v}\right) T\left(\lambda, \theta_{s}\right) \varepsilon(\lambda) \operatorname{BRDF}\left(\lambda_{r e f}\right)$.

This implies:

$R_{g}(\lambda)=\frac{T\left(\lambda, \theta_{v}\right) T\left(\lambda, \theta_{s}\right) \varepsilon(\lambda)}{T\left(\lambda_{\mathrm{NIR}}, \theta_{v}\right) T\left(\lambda_{\mathrm{NIR}}, \theta_{s}\right) \varepsilon\left(\lambda_{\mathrm{NIR}}\right)} R_{g}\left(\lambda_{\mathrm{NIR}}\right)$.

Therefore, the parameter $\alpha$ in Eq. (7) can be explicitly formulated as follows:

$\alpha\left(\lambda_{\mathrm{NIR}} \rightarrow \lambda\right)=\frac{T\left(\lambda, \theta_{v}\right) T\left(\lambda, \theta_{s}\right) \varepsilon(\lambda)}{T\left(\lambda_{\mathrm{NIR}}, \theta_{v}\right) T\left(\lambda_{\mathrm{NIR}}, \theta_{s}\right) \varepsilon\left(\lambda_{\mathrm{NIR}}\right)}$.

In Fig. 7, the parameter $\alpha$ is shown for the optical properties of an atmosphere including air molecules and aerosols. The value of the aerosol optical thickness at $550 \mathrm{~nm}$ is 0.1 and the Angström exponents used are 0 (typical of coarse aerosols) and 1.5 (typical of fine aerosols). It is worth noting that the spectral variation of the BRDF (i.e., the $\varepsilon$ ratio) must be accounted for in the calculation of $\alpha$. In (Hu, 2011), $\alpha$ was set after error and trial on a series of MODIS images over the gulf of Mexico. The following values $0.73,0.87$ and 0.93 were proposed by (Hu, 2011) for $\alpha$ at 469, 555 and $645 \mathrm{~nm}$ respectively (see Fig. 7). The values retrieved by $(\mathrm{Hu}, 2011)$ are in good agreement with those calculated here for an Angström exponent value of 0 (which is representative of coarse marine aerosols). It can be observed in Fig. 7 that values of $\alpha$ vary significantly with the type of aerosols (which is characterized here by the Angström exponent). Therefore, the spectral properties of aerosols must be accounted for in order to accurately retrieve the values of $\alpha$ for removing the sunglint contribution.

The deglinting method of (Hochberg et al., 2003; Hedley et al., 2005) described Section 2.4 is applied here to the Sentinel-2 image of Fig. 3a over the AERONET-OC site of Venice (Fig. 8). This method is hereafter referred to as Hedley-like procedure. The selected region of the image used for the calculation of $\alpha$ and $\beta$ is shown in Fig. 8b; this region was selected because of the large variation of the $R_{t}$ values at $865 \mathrm{~nm}$, thus indicating a noticeable variation of the sunglint contamination among the pixels. Once the GRS atmospheric correction (i.e., subtraction of the atmospheric radiance only, see Eq. (8)) is applied, the retrieved values of $\alpha$ and $\beta$ are used for removing the sunglint. The resulting corrected RGB image is shown in Fig. 8c. The visual and qualitative inspection of the processed image reveals that the strong discontinuous sunglint patterns are satisfactorily removed with the Hedley-like procedure coupled with the atmospheric correction part of the GRS algorithm. However, the retrieved $\alpha$ values are in disagreement with the expected theoretical values calculated according to the AERONET data and the geometry of observation of Sentinel-2 acquisition (Fig. 9a). To examine more quantitatively the performances of the Hedley-like procedures, the spectra of $L_{W N}$ obtained for pixels surrounding the AERONET-OC site are shown in Fig. 9b. The spectra retrieved from the GRS sunglint correction show less dispersion and are in a better agreement with the AERONET-OC measurements than those retrieved following the Hedley-like scheme. This can be partly explained by the difference between the retrieved $\alpha$ values and the theoretically expected ones but also by the choice of the $\beta$ value corresponding to the minimum value of $L_{W N}$ at $865 \mathrm{~nm}$ in the selected region of the image.

It is important to note that the performance of the Hedley-like method depends on the selection of the region of interest (ROI) used to perform the regression calculations to retrieve $\alpha$ and $\beta$. This selection is based on two hypothesis (i) spatial homogeneity of water-leaving radiances and (ii) presence of both glinted and glint-free pixels. However, the selection has to be done by visual inspection of the image which can be arbitrary. This is one of the major difference with the per-pixel-based GRS method which could be more easily automatically implemented. Potential better performances of the Hedley-like procedure might have been reached with other ROI used within the procedure. For instance, a better agreement between the retrieved $L_{W N}$ and the AERONET-OC data can be obtained when $\beta$ is set as the 10th percentile of $R_{t}$ at $865 \mathrm{~nm}$ (to limit impact of noise in the lowest values) instead of taking the strict minimum value of $R_{t}(865 \mathrm{~nm})$ within the ROI. The Hedley-like method is therefore considered as an efficient tool to process images where a

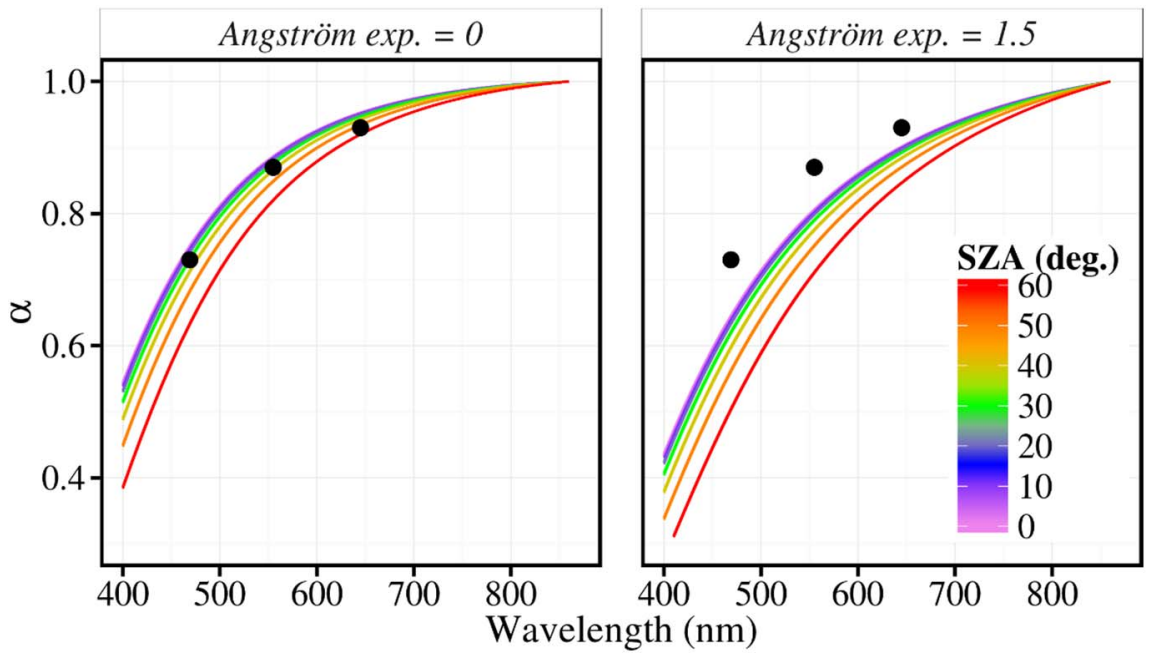

Fig. 7. Parameter $\alpha$ (unitless) describing the spectral variation of the sunglint reflectance at the top of the atmosphere from theoretical calculations (Eq. (19)) (colored lines) and from the values retrieved empirically by (Hu, 2011) (black dots). Calculations were performed for two values of the Angström exponent of 0 and 1.5, for a viewing angle of $10^{\circ}$ and several solar zenith angles (colors). (For interpretation of the references to color in this figure legend, the reader is referred to the web version of this article.) 
(a)

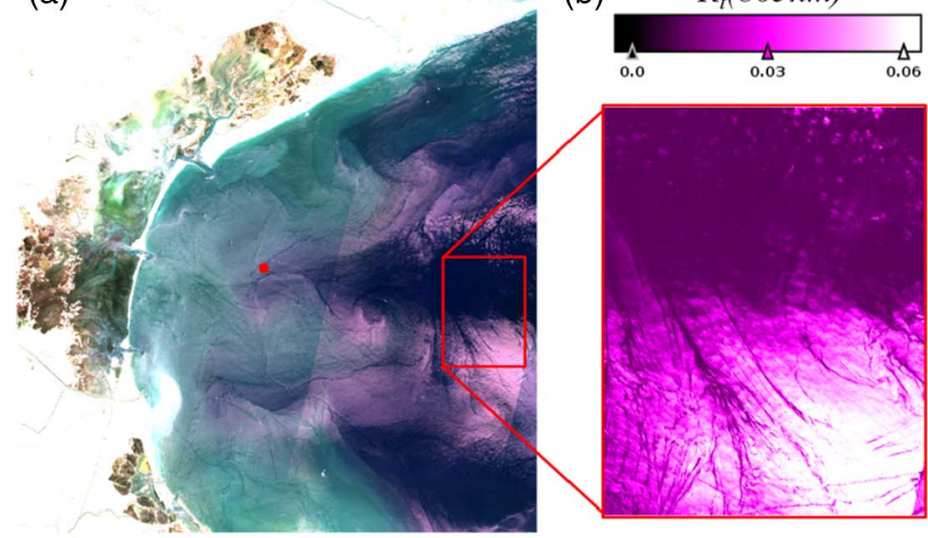

(c)

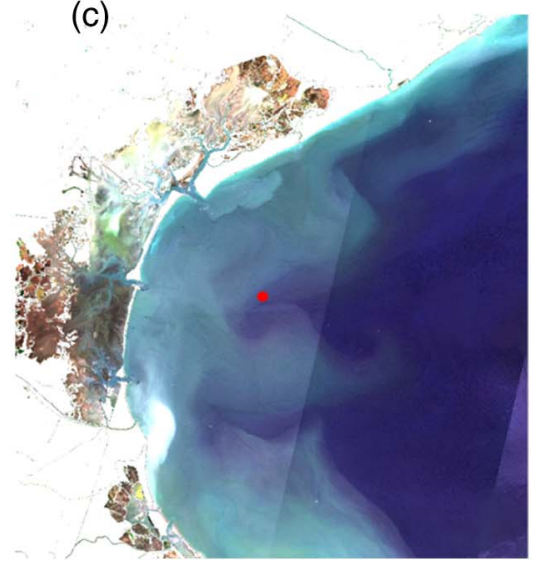

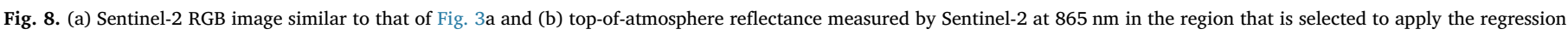
calculation of the Hedley et al. (2005) procedure. (c) RGB image after application of the Hedley-like method for removing the sunglint.

priori knowledge on the water-leaving radiance distribution over the image can be used. Additionally, the Hedley-like method needs to be accompanied by a proper atmospheric correction where the aerosol signal must be estimated to retrieve the water-leaving radiance at the sea surface. Conversely, the GRS method can be applied regardless of the $L_{W N}$ distribution and, thereby, is more suitable for an operational use like the processing of full archive of Sentinel-2 like satellite imagery.

\subsection{Consideration of exogenous aerosol data for an operational use of GRS algorithm}

Sunglint correction needs to be performed together with a specific atmospheric correction algorithm (i.e., removal of the atmospheric radiance) in order to retrieve the water-leaving radiances from satellite measurements. As mentioned in Section 3, prior knowledge on the aerosol optical thickness is required in GRS algorithm to derive $L_{W N}$ from top-of-atmosphere radiances (Fig. 2). Note that additional information on aerosol load and type is also needed for the Hedley-like methods (i.e., regression analyses) to correct for the atmospheric radiance in the visible and to retrieve the proper water-leaving radiance (see Section 5.1). Note also that the use of ancillary data (e.g., surface pressure, gas concentration data) as inputs of inverse algorithms is virtually systematic to derive level 2 geophysical products for most of the ocean color satellite sensors (e.g., MODIS, MERIS, VIIRS) and so, it is not so surprising that GRS algorithm requires ancillary data as far as these data are correctly documented elsewhere. In the results presented Section 4, the aerosol optical thickness data from the ground-based AERONET network were used to process the Sentinel-2 data. Unfortunately, the AERONET network is not dense enough to provide data in the vicinity of most inland reservoirs, lakes or coastal water. The lack of coincident (in time and space) aerosol data may reduce the operational use of the GRS algorithm to process Sentinel-2-like data archive. Another source for considering exogenous data for aerosol optical thickness is the large datasets generated in the framework of global circulation models and/or assimilation techniques using groundbased and remote sensing datasets. As an example, the Copernicus Atmosphere Monitoring Service (CAMS) provides through the European Centre for Medium-range Weather Forecast (ECMWF) data server realtime analyses and forecasts of aerosol optical thickness, $\tau_{a}$, starting from year 2003 (Flemming et al., 2017). Interestingly, it has been recently shown that hourly $\tau_{a}$ values of the CAMS dataset were highly consistent with AERONET in situ measurements (correlation coefficients around 0.86 except for urban sites where correlations are weaker) (Cesnulyte et al., 2014). Note that Cesnulyte et al. (2014) also pointed out that CAMS dataset might overestimate the contribution by coarse mode aerosols.

Here, the consideration of the CAMS aerosol optical thickness dataset rather than AERONET aerosol data is examined to make the GRS algorithm operational for a systematic processing of Sentinel-2-like satellite data. For that purpose, the AERONET aerosol optical thickness data is replaced by the spectral aerosol optical thickness data provided by the CAMS dataset. Note that the use of the CAMS data induced a retrieval of negative water-leaving radiances before removing the sunglint component (i.e., during the step of the subtraction of the atmospheric radiance from top-of-atmosphere radiation) for 21 satellite images over a total of 150 (i.e., $14 \%$ of our satellite dataset). As a result, these images have been discarded from the analysis. Matchup comparisons between the satellite water-leaving radiance $L_{W N}$ derived by GRS algorithm when CAMS ancillary aerosol data are used and in situ water-leaving radiance measured by AERONET-OC photometers are carried out in the same way as it was shown in Figs. 5 and 6. A summary of the statistical indicators of the matchup comparison is provided Table 3. Table 3 also shows the impact of the sunglint removal on the (a)

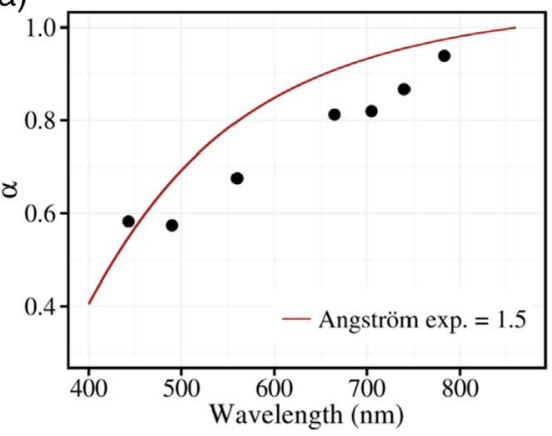

(b)

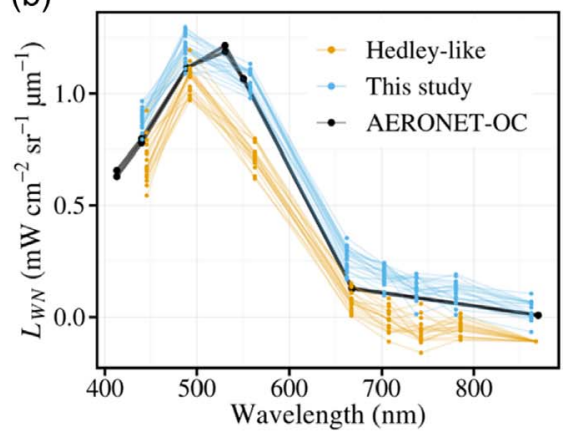

Fig. 9. (a) Retrieved $\alpha$ values from regression relationships obtained from the selected region illustrated in Fig. 8b (black dots) and simulated $\alpha$ values (Eq. (19)) using the AERONET aerosol data for the viewing geometry of the image (red line). (b) Normalized water-leaving radiances retrieved after applying (i) the full GRS algorithm (this study) and (ii) the Hedley et al. (2005) procedure (Hedley-like) to remove the sunglint component for which the GRS atmospheric correction module was used to remove the atmospheric radiance component. A comparison with the collocated measurements of the AERONET-OC system is also shown. (For interpretation of the references to color in this figure legend, the reader is referred to the web version of this article.) 
Table 3

Summary of the statistical parameters for the comparison between $L_{W N}$ derived from the Sentinel-2 data and $L_{W N}$ measured in situ from AERONET-OC system. Here, the GRS algorithm was applied using the aerosol optical thicknesses provided by the CAMS dataset. Note also that results are shown before and after removing the sunglint component. RMSE and bias are expressed in $\mathrm{mW} \cdot \mathrm{cm}^{-2} \cdot \mathrm{sr}^{-1} \cdot \mu \mathrm{m}^{-1}$.

\begin{tabular}{lllllll}
\hline $\begin{array}{l}\text { Spectral } \\
\text { band }\end{array}$ & & Regression line & $R^{2}$ & RMSE & NRMSE (\%) & Bias \\
\hline \multirow{2}{*}{$443 \mathrm{~nm}$} & Before & $0.60 \times+0.85$ & 0.126 & 1.000 & 146 & 0.578 \\
& After & $0.77 \times+0.35$ & 0.329 & 0.597 & 87.2 & 0.195 \\
$490 \mathrm{~nm}$ & Before & $0.82 \times+0.68$ & 0.395 & 0.898 & 88.2 & 0.489 \\
& After & $0.97 \times+0.08$ & 0.714 & 0.455 & 44.7 & 0.056 \\
$560 \mathrm{~nm}$ & Before & $0.92 \times+0.63$ & 0.545 & 0.898 & 81.3 & 0.535 \\
& After & $1.06 \times+0.02$ & 0.863 & 0.376 & 34.1 & 0.085 \\
$665 \mathrm{~nm}$ & Before & $0.93 \times+0.49$ & 0.263 & 0.782 & 276 & 0.469 \\
& After & $1.16 \times+0.04$ & 0.801 & 0.259 & 91.5 & 0.090 \\
$865 \mathrm{~nm}$ & Before & $-0.03 \times+0.33$ & $<0.0001$ & 0.514 & 2185 & 0.302 \\
& After & $1.31 \times+0.03$ & 0.214 & 0.104 & 4430 & 0.042 \\
\multirow{2}{*}{ All } & Before & $0.95 \times+0.51$ & 0.494 & 0.836 & 134 & 0.475 \\
& After & $1.01 \times+0.09$ & 0.778 & 0.396 & 63.6 & 0.094 \\
\hline
\end{tabular}

validation of satellite $L_{W N}$.

When the sunglint component is removed from satellite imagery, the overall correlation obtained between satellite and in situ $L_{W N}$ is satisfactory $\left(R^{2}=0.78\right)$. Such a correlation compares well with the case where AERONET aerosol optical thickness data are used as ancillary data $\left(R^{2}=0.87\right.$, Fig. 6 - all data). It should be noted as well that the impact of the sunglint removal on the validation of the retrieved satellite $L_{W N}$ is significant since much better determination coefficients $\left(R^{2}\right)$, regression slopes (i.e., they get closer to 1 ) and RMSE are obtained for each wavelength apart from the 865-nm band where $L_{W N}$ is fairly close to zero (Table 3). As a result, the overall performances of the GRS algorithm are maintained when using the CAMS aerosol data, thus facilitating the operational use of GRS-like algorithms. Exogenous data such as surface pressure or gas concentration from the CAMS database are commonly used in atmospheric correction algorithm. It has been shown here that CAMS aerosol optical thickness data can be safely used to correct Sentinel-2-like images for the sunglint radiances. In the near future, investigations should be carried out to reduce the use of aerosol ancillary data to better account for the real aerosol optical thickness corresponding to each satellite pixel. One way of achieving such a goal could be to use CAMS aerosol optical thickness data as a first guess within a more sophisticated inversion scheme than that used in the GRS algorithm. The spectral shape of the sunglint signal outlined earlier in this paper (Eq. (15) and Fig. A2b) would greatly help to derive both the aerosol optical properties and the sunglint radiance using a single algorithm.

\section{Conclusions and perspectives}

Due to the near-nadir view of the MSI/Sentinel-2 sensor, radiance data acquired by such a sensor are likely to be impacted by the reflection of direct sunlight on the air-water interface (so-called sunglint). Such a sunglint contribution thus needs to be accurately removed to retrieve the water-leaving radiance which is of primary interest for deriving the water optical properties and for monitoring the water quality. In this study, an algorithm, referred to as GRS, was proposed to remove the sunglint radiance for each pixel independently from Sentinel-2-like imagery over inland and sea waters, including targets at various altitudes.

In this study, the two SWIR bands of Sentinel-2 (centered on 1610 and $2190 \mathrm{~nm}$ ) were exploited for deriving the sunglint component and removing it from each band of the satellite image. To this end, the spectral variation of the sunglint contribution over a large spectral range from 350 to $2500 \mathrm{~nm}$ has been first revisited in this study. We found that the bidirectional reflectance distribution function (BRDF) of the sunglint varies by $>28 \%$ between the SWIR and the blue bands of
Sentinel-2. Based on these results on the spectral properties of the BRDF, the sunglint signal can be extrapolated from the SWIR to the visible and NIR part of the spectrum to correct for the Sentinel-2 bands. In addition to removing the sunglint radiance, the GRS algorithm also enables to correct the top-of-atmosphere satellite radiance for the atmospheric radiance and sky reflection onto the water surface provided that a prior knowledge of the aerosol optical properties is available. The aerosol optical thickness values were taken from the AERONET photometer network but also from the CAMS dataset to process the Sentinel-2 images shown in the paper.

Application of the method to inland and coastal sites highlighted that the sunglint patterns are satisfactorily removed from a qualitative point of view over the image extent. As an example, it has been shown that sunglint contribution induced by ship wakes can be quasi-fully eliminated. The quantitative validation of the GRS algorithm has been carried out using matchup comparisons between satellite and in situ measurements of the water-leaving radiance using a number of 150 images acquired over various AERONET-OC sites. The matchup comparison showed that the application of GRS algorithm improves by $55 \%$ the correlation between the water-leaving radiances retrieved from Sentinel-2 and those measured in situ. The discrepancies between satellite and in situ measurements were reduced by $60 \%$ in terms of RMSE and bias. These results thus showed that the water-leaving radiances are retrieved from the Sentinel-2 data with performances that are expected for the current "ocean color" missions (e.g., MODIS, VIIRS). However, Sentinel-2 has the main advantage to acquire data at a much higher spatial resolution $(<60 \mathrm{~m})$ than current ocean color sensors $(>300 \mathrm{~m})$.

In the current version of the GRS algorithm, prior knowledge of the aerosol optical thickness is needed. Such an issue was overcome by taking ground-based AERONET aerosol measurements or aerosol data from global reanalysis and forecasts datasets such as the CAMS dataset. In particular, it was shown that the use of the global CAMS dataset enables the operational use of the GRS algorithm to correct for Sentinel2 archive systematically. The main limitation of the proposed method is the need of a priori information on the aerosol optical properties. Further developments could consist in linking the sunglint removal procedure with a proper atmospheric correction algorithm that will be capable of estimating the aerosol optical properties (e.g., spectral optical thicknesses) directly from each pixel. It should be also noted that further works are needed to take into account the small angle differences that could exist between the MSI spectral bands when the BRDF is calculated by GRS algorithm.

The GRS method has been implemented here for the MSI/Sentinel-2 specifications but could be easily applied to similar types of satellite sensors (e.g., availability of SWIR bands). Among the existing missions with decameter spatial resolution, the series of Landsat satellites (from Landsat-4 TM to Landsat-8) is interesting since these sensors are equipped with SWIR channels. Interesting applications could also be foreseen for the aerosol/ocean color current missions having a lower spatial resolution than Sentinel-2 or Landsat, such as MODIS or Sentinel-3 (combining the OLCI and SLSTR sensors) for which more accurate aerosol optical properties could be retrieved.

\section{Acknowledgments}

This work was supported by the Centre National d'Etudes Spatiales (CNES) through the TOSCA-project "TELQUEL" and by the Agence Française pour la Biodiversite (AFB). The authors would like to thank the European Space Agency (ESA) for providing the Sentinel-2 data and the AERONET and AERONET-OC teams as well as the Principle Investigators of the sites used in this work for providing their data. The Step forum (http://forum.step.esa.int) and Marco Peters are also greatly acknowledged for their useful help to process Sentinel-2 data with the snappy API. The authors are very grateful to Olivier Hagolle for providing open source codes to perform gaseous absorption 
correction and massive Sentinel-2 data download. Thanks are also exthe manuscript. tended to the anonymous reviewers, whose comments greatly improved

\section{Appendix A. Appendix}

One of the source of spectral variability of the sunglint comes from the BRDF of the air-sea which is discusses in this Appendix.

Let us consider $n$ as the refractive index of water relative to air and $\omega$ the incident angle of sunlight reaching a wave facet. For a given geometry of observation, the sunglint radiance reaching the satellite sensor has undergone specular reflections on the appropriate wave facets for the incident angle $\omega$ which can be calculated from the geometry of observation:

$\cos 2 \omega=\cos \theta_{s} \cos \theta_{v}+\sin \theta_{s} \sin \theta_{v} \cos \Delta \varphi$.

Given that the incident sunlight is unpolarized, the Fresnel's reflection coefficient $R_{f}$, introduced in Eq. (5), can be expressed as follows:

$R_{f}(\omega)=\frac{r_{\|}(\omega)^{2}+r_{\perp}(\omega)^{2}}{2}$,

where $r_{\perp}$ and $r_{\|}$are the perpendicular and parallel components of the Fresnel coefficients with respect to the plane of incidence, respectively, which are defined as:

$r_{\perp}(\omega)=\frac{\cos \omega-\sqrt{n^{2}-\sin ^{2} \omega}}{\cos \omega+\sqrt{n^{2}-\sin ^{2} \omega}}$,
$r_{\|}(\omega)=\frac{\sqrt{n^{2}-\sin ^{2} \omega}-n^{2} \cos \omega}{\sqrt{n^{2}-\sin ^{2} \omega}+n^{2} \cos \omega}$.

As it can be seen from Eq. (5), the spectral behavior of the reflection coefficient is only driven by the refractive index of the natural water, $n$. The spectral variation of $n$ can have a significant impact on the sunglint signal when dealing with visible to SWIR measurements. A variation of $5 \%$ for instance can induce a strong spectral dependence of the Fresnel reflection coefficient $R_{f}$ due to the non-linearity of Eq. (A3).

The characterization of the spectral variation of $n$ over wavelengths ranging from the visible (VIS) to the SWIR part of the spectrum has proven to be a challenging task (Austin and Halikas, 1976; Segelstein, 1981; Bertie and Lan, 1996; Ball, 2008; Max and Chapados, 2009). However, it has been recently shown that the concatenation of the different datasets or parameterizations provides a practical means to express the refractive index for a realistic range of temperature and salinity over the VIS-to-SWIR range (Röttgers et al., 2011). Here, a similar method is used based on three studies of reference (Quan and Fry, 1995; Max and Chapados, 2009; Kedenburg et al., 2012) to deal with the spectral variation of the refractive index.

The effect of temperature and salinity were evaluated and parameterized by Quan and Fry (Quan and Fry, 1995). This formulation, denoted as $n_{Q F 1995}(T, S)$, was shown to be valid for the spectral range of 200-1100 nm (Huibers, 1997). Kedenburg et al. (Kedenburg et al., 2012) accurately parametrized the refractive index of distilled water, hereafter referred to as $n_{K 2012}$, at $20^{\circ} \mathrm{C}$ for wavelength region between $500 \mathrm{~nm}$ and $1750 \mathrm{~nm}$. Max and Chapados (Max and Chapados, 2009) established reference values for pure water, hereafter denoted as $n_{M C 2009}$, at $25^{\circ} \mathrm{C}$ in the SWIR for wavelengths larger than $1600 \mathrm{~nm}$. These three formulations are concatenated over the $0.4-2.5 \mu \mathrm{m}$ spectral range following (Röttgers et al., 2011):

$\left\{\begin{array}{l}n_{1}(T, S ; \lambda)=n_{Q F 1995}(T, S ; \lambda) \\ n_{2}(T, S ; \lambda)=n_{K 2012}(\lambda)+\left[n_{1}(T, S ; 800 \mathrm{~nm})-n_{K 2012}(800 \mathrm{~nm})\right] \\ n_{3}(T, S ; \lambda)=n_{M C 2009}(\lambda)+\left[n_{2}(T, S ; 1600 \mathrm{~nm})-n_{M C 2009}(1600 \mathrm{~nm})\right]\end{array}\right.$

where $T, S$ and $\lambda$ are temperature, salinity and wavelength respectively. The refractive index is then determined by the distribution:

$n(T, S ; \lambda)=\left\{\begin{array}{l}n_{1}(T, S ; \lambda) \text { if } \lambda<800 \mathrm{~nm} \\ n_{2}(T, S ; \lambda) \text { if } 800 \mathrm{~nm} \leq \lambda<1600 \mathrm{~nm} . \\ n_{3}(T, S ; \lambda) \text { if } \lambda \geq 1600 \mathrm{~nm}\end{array}\right.$

From this distribution, the spectral variation of $n$ over the range 350 to $2500 \mathrm{~nm}$ is about 0.09 in absolute values (i.e., the value of $n$ varies from

(a)

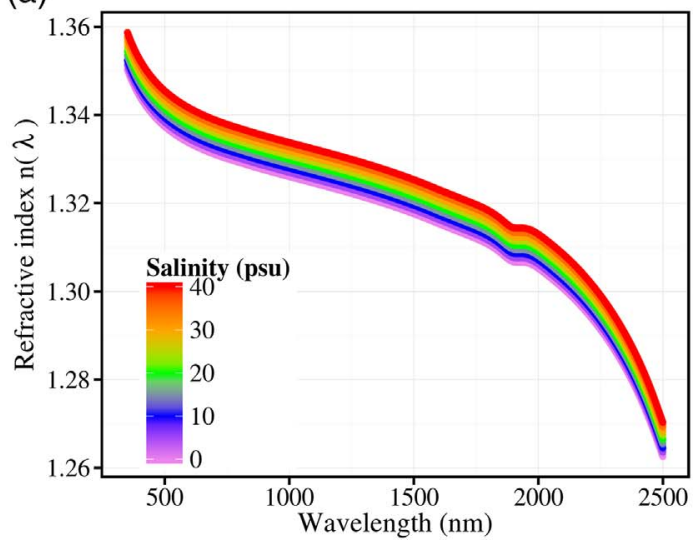

(b)

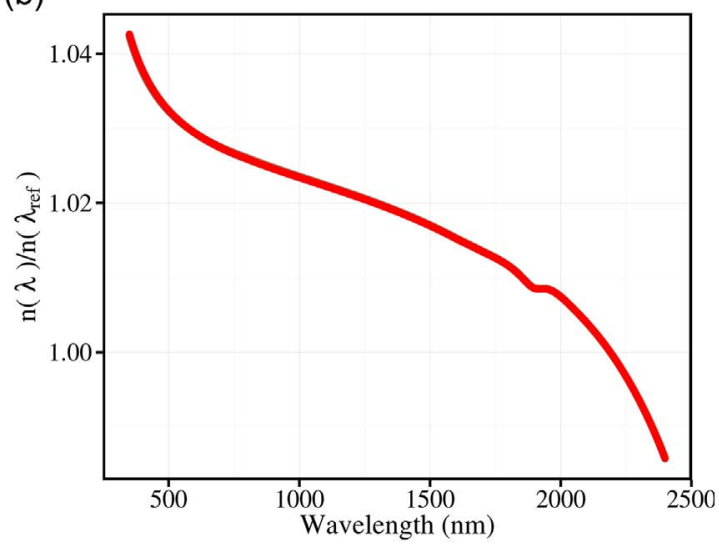

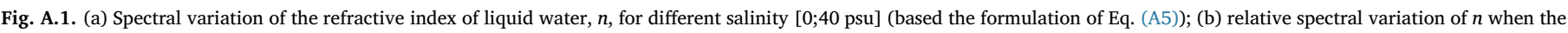
refractive index is normalized to its value at $\lambda_{\text {ref }}=2190 \mathrm{~nm}$. Note that the variations due to salinity and temperature are smaller than the line thickness in Fig. A.1b. 
(a)

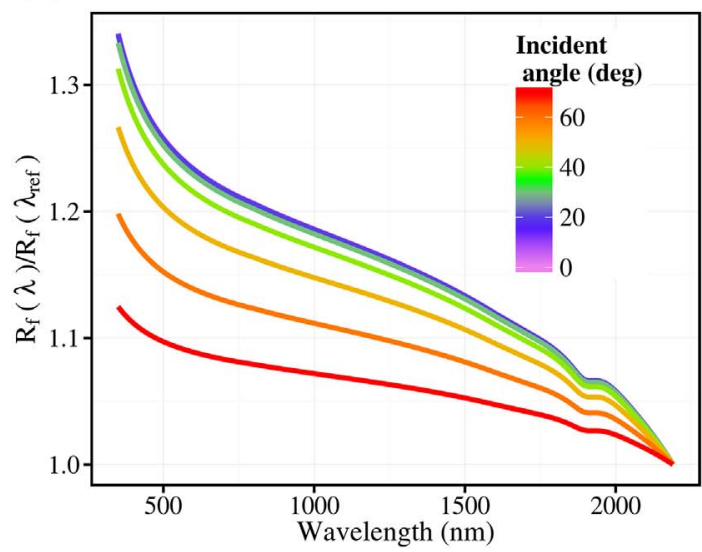

(b)

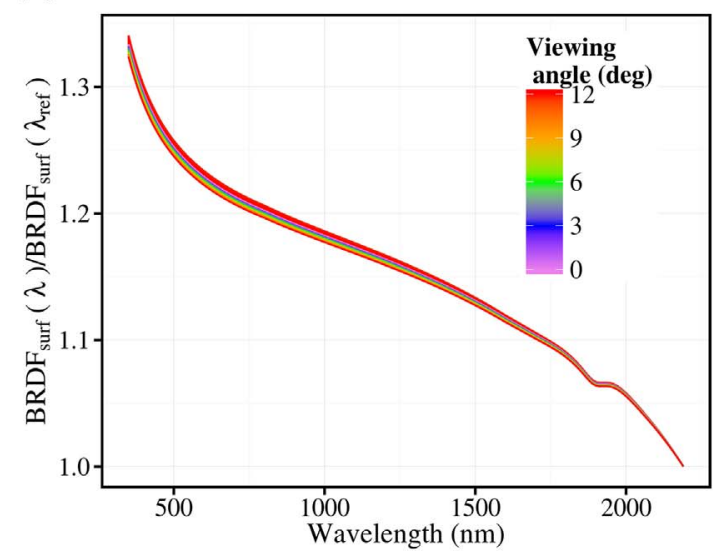

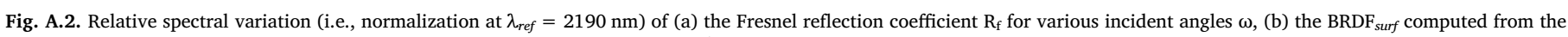
Cox and Munk wave slope distribution for wind speed ranging from 0 to $12 \mathrm{~m} \cdot \mathrm{s}^{-1}$ and for various viewing angles $\theta_{v}$.

1.27 to 1.36, Fig. A.1a) which corresponds to a relative variation of $4.3 \%$ (Fig. A.1b). The sensitivity of $n$ with salinity, which is varied from 0 to $40 \mathrm{psu}$, is also shown in Fig. A.1a. Typically, the variation of $n$ with the salinity increasing from 0 to 40 psu is of 0.01 in absolute values ( $0.8 \%$ in relative values), which remains very weak in comparison to the impact of the wavelength. Note that the sensitivity of $n$ with a temperature comprised between $0^{\circ}$ and $35^{\circ} \mathrm{C}$ is so small relatively to that of salinity that it could not be discernable in Fig. A.1a. As result, the sunglint spectral variation is not significantly impacted by changes in salinity or temperature.

Then, the $R_{f}$ coefficients were calculated for various incident angles of the sunlight beam and for the refractive index values shown in Fig. A.1a (see Fig. A.2a). The relative spectral variations of $R_{f}$ show a variation of $10 \%$ for grazing incident angles $\left(\sim 70^{\circ}\right)$ and of $>35 \%$ when the incident light is nearly perpendicular to the wave facet. Results confirm the significant dependence of the spectral variation of the sunglint radiation $(\sim 35 \%)$ due to the spectral variations of the water refractive index, which was yet shown to be around $4 \%$ only over the spectrum 350 to 2500 nm.

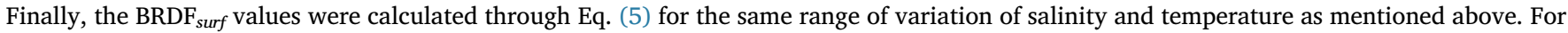
these calculations, the function $q$ of Eq. (5) corresponds to 2-dimensional Cox and Munk (CM) model (Cox and Munk, 1954b) which provides the wave slope distributions as a function of the wind speed and direction. It is important to recall that the CM model relationship between surface wind and sea roughness might be not applicable for decameter-scale pixel. However, the CM parameterization remains efficient to model realistic wave spectra including long gravity to short capillary waves irrespective of the spatial scale (Munk, 2009; Lin et al., 2016). Here, the wind speed input used with the CM model is not taken as an actual wind value but as a mathematical parameter enabling us to obtain a wide range of realistic sea roughness encompassing a large range of variance, kurtosis and skewness of the wave slope distribution. Thus, the BRDF $_{\text {surf }}$ values were calculated for wind speed values ranging from 0 to $12 \mathrm{~m} \cdot \mathrm{s}^{-1}$. Note that the wave shadowing effects was also accounted for through the Sancer model (Sancer, 1969). The viewing angle range was limited to that of the MSI/Sentinel-2 sensor (i.e., $\theta_{v} \leq 12^{\circ}$ ) and a full range of azimuth $\Delta \varphi$ was considered (i.e., $0^{\circ}$ to $360^{\circ}$ by step of $5^{\circ}$ ). Values of the solar zenith angles $\theta_{s}$ beyond $60^{\circ}$ were excluded from the computation since the validity of the version of Cox and Munk model that does not account for multiple reflections may be questionable (Mobley, 2015).

Let us introduce the spectral ratio of the BRDF $\varepsilon$ :

$\varepsilon=\operatorname{BRDF}_{\text {surf }}(\lambda) / \operatorname{BRDF}_{\text {surf }}\left(\lambda_{\text {ref }}\right)$

where the reference wavelength $\lambda_{\text {ref }}$ is fixed to $2190 \mathrm{~nm}$ (last SWIR band of Sentinel-2) in the following. The ratio $\varepsilon$ is shown in Fig. A.2b to highlight the BRDF spectral dependence. It is remarkable that the $\varepsilon$ ratio is very slightly dependent on the viewing angle $\theta_{v}$ in comparison to the variation of the Fresnel coefficient with the incident angle $\omega$ (Fig. A.2a). This is because the maximum incident angle $\omega$ that is capable of generating sunglint for $\theta_{v} \leq 12^{\circ}$ and $\theta_{s} \leq 60^{\circ}$ is smaller than $36^{\circ}$ (see Eq. (A1)). As it can be seen Fig. A.2a, the Fresnel coefficient varies weakly within this angular range $\left(0^{\circ}\right.$ to $\left.36^{\circ}\right)$ for a given wavelength. As a result, it was noted that the sunglint spectral variation is not significantly impacted by the viewing geometry of observation of the Sentinel-2 platform (i.e., near-nadir viewing angles). Therefore, the sunglint signal can be handled from the visible to SWIR measurements in the case of MSI/Sentinel-2 configuration independently of water temperature and salinity. The same demonstration can be done for Landsat platform.

\section{References}

Austin, R.W., Halikas, G., 1976. The Index of Refraction of Seawater. Scripps Inst. Oceanogr., La Jolla, pp. 124.

Ball, P., 2008. Water: water - an enduring mystery. Nature 452 (7185), 291-292. http:// dx.doi.org/10.1038/452291a.

Bertie, J.E., Lan, Z., 1996. Infrared intensities of liquids XX: the intensity of the $\mathrm{OH}$ stretching band of liquid water revisited, and the best current values of the optical constants of $\mathrm{H}_{2} \mathrm{O}(1)$ at $25^{\circ} \mathrm{C}$ between 15,000 and $1 \mathrm{~cm}^{-1}$. Appl. Spectrosc. 50 (8), 1047-1057. http://dx.doi.org/10.1366/0003702963905385.

Bodhaine, B.A., Wood, N.B., Dutton, E.G., Slusser, J.R., 1999. On Rayleigh optical depth calculations. J. Atmos. Ocean. Technol. 16 (11), 1854-1861. http://dx.doi.org/10. 1175/1520-0426(1999)016<1854:ORODC > 2.0.CO;2.

Breon, F.M., Henriot, N., 2006. Spaceborne observations of ocean glint reflectance and modeling of wave slope distributions. J. Geophys. Res. 111, C06005.

Cesnulyte, V., Lindfors, A.V., Pitkänen, M.R.A., Lehtinen, K.E.J., Morcrette, J.J., Arola, A.,
2014. Comparing ECMWF AOD with AERONET observations at visible and UV wavelengths. Atmos. Chem. Phys. 14 (2), 593-608. http://dx.doi.org/10.5194/acp-14593-2014.

Chami, M., Lafrance, B., Fougnie, B., Chowdhary, J., Harmel, T., Waquet, F., 2015. OSOAA: a vector radiative transfer model of coupled atmosphere-ocean system for a rough sea surface application to the estimates of the directional variations of the water leaving reflectance to better process multi-angular satellite data over the ocean. Opt. Express 23 (21), 27829-27852. http://dx.doi.org/10.1364/OE.23. 027829.

Cox, C., Munk, W., 1954a. Measurement of the roughness of the sea surface from photographs of the Sun's glitter. J. Opt. Soc. Am. 44 (11), 838-850. http://dx.doi.org/10. 1364/JOSA.44.000838.

Cox, C., Munk, W., 1956. In: Cox, C., Munk, W. (Eds.), Slopes of the Sea Surface Deduced From Photographs of Sun Glitter. Scripps Institution of Oceanography.

Cox, C., Munk, W.H., 1954b. Statistics of the sea surface derived from sun glitter. J. Mar Res. 13 (2), 198-227.

Dee, D.P., et al., 2011. The ERA-interim reanalysis: configuration and performance of the 
data assimilation system. Q. J. R. Meteorol. Soc. 137 (656), 553-597. http://dx.doi. org/10.1002/qj.828.

Drusch, M., et al., 2012. Sentinel-2: ESA's optical high-resolution mission for GMES operational services. Remote Sens. Environ. 120, 25-36. http://dx.doi.org/10.1016/j. rse.2011.11.026.

Eck, T.F., Holben, B.N., Reid, J.S., Dubovik, O., Smirnov, A., O'Neill, N.T., Slutsker, I., Kinne, S., 1999. Wavelength dependence of the optical depth of biomass burning, urban, and desert dust aerosols. J. Geophys. Res. 104, 31333-31349.

Flemming, J., et al., 2017. The CAMS interim reanalysis of carbon monoxide, ozone and aerosol for 2003-2015. Atmos. Chem. Phys. 17 (3), 1945-1983. http://dx.doi.org/ 10.5194/acp-17-1945-2017.

Fukushima, H., Suzuki, K., Li, L., Suzuki, N., Murakami, H., 2009. Improvement of the ADEOS-II/GLI sun-glint algorithm using concomitant microwave scatterometer-derived wind data. Adv. Sp. Res. 43 (6), 941-947.

Gatebe, C.K., Wilcox, E., Poudyal, R., Wang, J., 2011. Effects of ship wakes on ocean brightness and radiative forcing over ocean. Geophys. Res. Lett. 38 (17), L17702. http://dx.doi.org/10.1029/2011GL048819.

Goodman, J.A., Lee, Z., Ustin, S.L., 2008. Influence of atmospheric and sea-surface corrections on retrieval of bottom depth and reflectance using a semi-analytical model: a case study in Kaneohe Bay, Hawaii. Appl. Opt. 47 (28), F1. http://dx.doi.org/10 1364/AO.47.0000F1.

Gordon, H.R., 1997. Atmospheric correction of ocean color imagery in the Earth Observing System era. J. Geophys. Res. 102 (D14), 17081-17106.

Gordon, H.R., Clark, D.K., Brown, J.W., Brown, O.B., Evans, R.H., Broenkow, W.W., 1983. Phytoplankton pigment concentration in the Middle Atlantic Bight: comparison of ship determinations and CZCS estimates. Appl. Opt. 22 (1), 20-36.

Goyens, C., Jamet, C., Schroeder, T., 2013. Evaluation of four atmospheric correction algorithms for MODIS-Aqua images over contrasted coastal waters. Remote Sens. Environ. 131, 63-75.

Hale, G.M., Querry, M.R., 1973. Optical constants of water in the $200-\mathrm{nm}$ to $200-\mu \mathrm{m}$ wavelength region. Appl. Opt. 12 (3), 555.

Harmel, T., Chami, M., 2013. Estimation of the sun glint radiance field from optical satellite imagery over open ocean: multidirectional approach and polarization aspects J. Geophys. Res. 118 (1), 1-15 (doi:10.1029/2012JC008221).

Hedley, J.D., Harborne, A.R., Mumby, P.J., 2005. Technical note: simple and robust removal of sun glint for mapping shallow-water benthos. Int. J. Remote Sens. 26 (10), 2107-2112. http://dx.doi.org/10.1080/01431160500034086.

Heege, T., Fischer, J., 2000. Sun glitter correction in remote sensing imaging spectrometry. In: SPIE Ocean Optics XV Conference, Monaco.

Hlaing, S., Harmel, T., Gilerson, A., Foster, R., Weidemann, A., Arnone, R., Wang, M., Ahmed, S., 2013. Evaluation of the VIIRS ocean color monitoring performance in coastal regions. Remote Sens. Environ. 139, 398-414.

Hochberg, E.J.J., Andrefouet, S., Tyler, M.R.R., 2003. Sea surface correction of high spatial resolution Ikonos images to improve bottom mapping in near-shore environments. Geosci. Remote Sensing, IEEE Trans. 41 (7), 1724-1729. http://dx.doi. org /10.1109/TGRS.2003.815408.

Holben, B.N., Eck, T.F., Slutsker, I., Tanre, D., Buis, J.P., Setzer, A., Vermote, E., Reagan, J.A., Kaufman, Y.J., Nakajima, T., 1998. AERONET-a federated instrument network and data archive for aerosol characterization. Remote Sens. Environ. 66 (1), 1-16.

Hollingsworth, A., et al., 2008. Toward a monitoring and forecasting system for atmospheric composition: the GEMS project. Bull. Am. Meteorol. Soc. 89 (8), 1147-1164. http://dx.doi.org/10.1175/2008BAMS2355.1.

$\mathrm{Hu}, \mathrm{C} ., 2011$. An empirical approach to derive MODIS ocean color patterns under severe sun glint. Geophys. Res. Lett. 38 (1), L01603. http://dx.doi.org/10.1029/ 2010GL045422.

Huibers, P.D., 1997. Models for the wavelength dependence of the index of refraction of water. Appl. Opt. 36 (16), 3785-3787. http://dx.doi.org/10.1364/AO.36.003785.

Kaufman, Y.J., Smirnov, A., Holben, B.N., Dubovik, O., 2001. Baseline maritime aerosol: methodology to derive the optical thickness and scattering properties. Geophys. Res. Lett. 28 (17), 3251-3256.

Kay, S., Hedley, J.D., Lavender, S., 2009. Sun glint correction of high and low spatial resolution images of aquatic scenes: a review of methods for visible and near-infrared wavelengths. Remote Sens. 1 (4), 697-730. http://dx.doi.org/10.3390/rs1040697.

Kedenburg, S., Vieweg, M., Gissibl, T., Giessen, H., 2012. Linear refractive index and absorption measurements of nonlinear optical liquids in the visible and near-infrared spectral region. Opt. Mater. Express 2 (11), 1588-1611. http://dx.doi.org/10.1364/ OME.2.001588.

Kotchenova, S.Y., Vermote, E.F., Matarrese, R., Klemm, F.J., 2006. Validation of a vector version of the $6 \mathrm{~S}$ radiative transfer code for atmospheric correction of satellite data. Part I: path radiance. Appl. Opt. 45 (26), 6762-6774.

Kutser, T., Vahtmäe, E., Praks, J., 2009. A sun glint correction method for hyperspectral imagery containing areas with non-negligible water leaving NIR signal. Remote Sens. Environ. 113 (10), 2267-2274. http://dx.doi.org/10.1016/j.rse.2009.06.016.

Levy, R.C., Remer, L.A., Tanré, D., Mattoo, S., Kaufman, Y.J., 2009. Algorithm for Remote Sensing of Tropospheric Aerosol Over Dark Targets From MODIS: Collections 005 and 051: Revision 2; Feb 2009. Download from. http//modisatmos.gsfc.nasa.gov/_docs/ ATBD MOD04 C005 rev2.pdf.

Li, H., Pinel, N., Bourlier, C., 2013. Polarized infrared reflectivity of one-dimensional Gaussian sea surfaces with surface reflections. Appl. Opt. 52 (25), 6100. http://dx. doi.org/10.1364/AO.52.006100

Lin, Z., Li, W., Gatebe, C., Poudyal, R., Stamnes, K., 2016. Radiative transfer simulations of the two-dimensional ocean glint reflectance and determination of the sea surface roughness. Appl. Opt. 55 (6), 1206. http://dx.doi.org/10.1364/AO.55.001206.

Lyzenga, D.R., Malinas, N.P., Tanis, F.J., 2006. Multispectral bathymetry using a simple physically based algorithm. IEEE Trans. Geosci. Remote Sens. 44 (8), 2251-2259.
http://dx.doi.org/10.1109/TGRS.2006.872909.

Martin, J., Eugenio, F., Marcello, J., Medina, A., 2016. Automatic sun glint removal of multispectral high-resolution WorldView-2 imagery for retrieving coastal shallow water parameters. Remote Sens. 8 (1), 37. http://dx.doi.org/10.3390/rs8010037.

Max, J.-J.J., Chapados, C., 2009. Isotope effects in liquid water by infrared spectroscopy. III. $\mathrm{H}_{2} \mathrm{O}$ and $\mathrm{D}_{2} \mathrm{O}$ spectra from 6000 to $0 \mathrm{~cm}^{-1}$. J. Chem. Phys. 131 (18), 184505 (doi:10.1063/1.3258646).

Mélin, F., Zibordi, G., Berthon, J.F., 2007. Assessment of satellite ocean color products at a coastal site. Remote Sens. Environ. 110 (2), 192-215.

Mobley, C.D., 2015. Polarized reflectance and transmittance properties of windblown sea surfaces. Appl. Opt. 54 (15), 4828. http://dx.doi.org/10.1364/A0.54.004828.

Munk, W., 2009. An inconvenient sea truth: spread, steepness, and skewness of surface slopes. Annu. Rev. Mar. Sci. 1 (1), 377-415. http://dx.doi.org/10.1146/annurev. marine.010908.163940.

Ottaviani, M., Spurr, R., Stamnes, K., Li, W., Su, W., Wiscombe, W., 2008. Improving the description of sunglint for accurate prediction of remotely sensed radiances. J. Quant. Spectrosc. Radiat. Transf. 109 (14), 2364-2375.

Palmer, S.C.J., Kutser, T., Hunter, P.D., 2015. Remote sensing of inland waters: challenges, progress and future directions. Remote Sens. Environ. 157, 1-8 (doi:10.1016/ j.rse.2014.09.021).

Philpot, W., 2007. Estimating atmospheric transmission and surface reflectance from glint-contaminated spectral image. IEEE Trans. Geosci. Remote Sens. 45 (2), 448-457. http://dx.doi.org/10.1109/TGRS.2006.887161.

Plass, G.N., Kattawar, G.W., Guinn, J.A., 1975. Radiative transfer in the earth's atmosphere and ocean: influence of ocean waves. Appl. Opt. 14 (8), 1924. http://dx.doi. org/10.1364/AO.14.001924.

Quan, X., Fry, E.S., 1995. Empirical equation for the index of refraction of seawater. Appl. Opt. 34 (18), 3477-3480. http://dx.doi.org/10.1364/A0.34.003477.

Rahman, H., Dedieu, G., 1994. SMAC: a simplified method for the atmospheric correction of satellite measurements in the solar spectrum. Int. J. Remote Sens. 15 (1), 123-143. http://dx.doi.org/10.1080/01431169408954055.

Ross, V., Dion, D., Potvin, G., 2005. Detailed analytical approach to the Gaussian surface bidirectional reflectance distribution function specular component applied to the sea surface. J. Opt. Soc. Am. A 22 (11), 2442. http://dx.doi.org/10.1364/JOSAA.22. 002442.

Röttgers, R., Doerffer, R., McKee, D., Schönfeld, W., 2011. The Water Optical Properties Processor (WOPP): Pure Water Spectral Absorption and Real Part of Refractive Index Model, ATBD Algorithm Theor. Basis Doc. ESA/ESRIN. Vol. 1. pp. 1-20.

Roy, D.P., et al., 2014. Landsat-8: science and product vision for terrestrial global change research. Remote Sens. Environ. 145, 154-172. http://dx.doi.org/10.1016/j.rse. 2014.02.001.

Sancer, M., 1969. Shadow-corrected electromagnetic scattering from a randomly rough surface. IEEE Trans. Antennas Propag. 17 (5), 577-585.

Schaeffer, B.A., Schaeffer, K.G., Keith, D., Lunetta, R.S., Conmy, R., Gould, R.W., 2013. Barriers to adopting satellite remote sensing for water quality management. Int. J. Remote Sens. 34 (21), 7534-7544. http://dx.doi.org/10.1080/01431161.2013. 823524.

Segelstein, D.J., 1981. The Complex Refractive Index of Water.

Shi, W., Wang, M., 2009. An assessment of the black ocean pixel assumption for MODIS SWIR bands. Remote Sens. Environ. 113 (8), 1587-1597.

Thuillier, G., Herse, M., Labs, D., Foujols, T., Peetermans, W., Gillotay, D., Simon, P.C., Mandel, H., 2003. The solar spectral irradiance from 200 to $2400 \mathrm{~nm}$ as measured by the SOLSPEC spectrometer from the ATLAS and EURECA missions. Sol. Phys. 214 (1), $1-22$.

Tormos, T., Harmel, T., Danis, P.-A., Chami, M., 2015. Exploiting satellite image time series for monitoring ecological quality parameters of French reservoirs. In: Analysis of Multitemporal Remote Sensing Images (Multi-Temp). 2015 8th International Workshop IEEE, pp. 1-4.

Veselovskii, I., Kolgotin, A., Griaznov, V., Müller, D., Franke, K., Whiteman, D.N., 2004 Inversion of multiwavelength Raman Lidar data for retrieval of bimodal aerosol size distribution. Appl. Opt. 43 (5), 1180-1195.

Wang, M., 2016. Rayleigh radiance computations for satellite remote sensing: accounting for the effect of sensor spectral response function. Opt. Express 24 (11), 12414. http://dx.doi.org/10.1364/OE.24.012414.

Wang, M., Bailey, S.W., 2001. Correction of sun glint contamination on the SeaWiFS ocean and atmosphere products. Appl. Opt. 40 (27), 4790-4798.

Wang, M., Gordon, H.R., 1994. Radiance reflected from the ocean-atmosphere system: synthesis from individual components of the aerosol size distribution. Appl. Opt. 33 (30), 7088.

Wang, M.H., Shi, W., 2007. The NIR-SWIR combined atmospheric correction approach for MODIS ocean color data processing. Opt. Express 15 (24), 15722-15733.

Yang, H., Gordon, H.R., 1997. Remote sensing of ocean color: assessment of the waterleaving radiance bidirectional effects on the atmospheric diffuse transmittance. Appl Opt. 36, 7887-7897.

Zhang, H., Wang, M., 2010. Evaluation of sun glint models using MODIS measurements. J. Quant. Spectrosc. Radiat. Transf. 111 (3), 492-506.

Zibordi, G., Berthon, J.F., Mélin, F., D'Alimonte, D., Kaitala, S., 2009. Validation of satellite ocean color primary products at optically complex coastal sites: Northern Adriatic Sea, Northern Baltic Proper and Gulf of Finland. Remote Sens. Environ. 113 (12), 2574-2591.

Zibordi, G., et al., 2009. AERONET-OC: a network for the validation of ocean color primary radiometric products. J. Atmos. Ocean. Technol. 26, 1634-1651.

Zilman, G., Miloh, T., 2001. Kelvin and V-like ship wakes affected by surfactants. J. Sh. Res. 45 (2), 150-163. 